\title{
Progressive Collapse Analysis of Steel Structures under Fire Conditions
}

By Ruirui Sun ${ }^{1, *}$, Zhaohui Huang ${ }^{2}$ and Ian Burgess ${ }^{3}$

\begin{abstract}
In this paper a robust static-dynamic procedure has been developed. The development extends the capability of the Vulcan software to model the dynamic and static behaviour of steel buildings during both local and global progressive collapse of the structures under fire conditions. The explicit integration method was adopted in the dynamic procedure. This model can be utilized to allow a structural analysis to continue beyond the temporary instabilities which would cause singularities in the full static analyses. The automatic switch between static and dynamic analysis makes the Vulcan a powerful tool to investigate the mechanism of the progressive collapse of the structures generated by the local failure of components. The procedure was validated against several practical cases. Some preliminary studies of the collapse mechanism of steel frame due to columns' failure under fire conditions are also presented. It is concluded that for un-braced frame the lower loading ratio and bigger beam section can give higher failure temperature in which the global structural collapse happens. However, the localised collapse of the frame with the higher loading ratio and smaller beam section can more easily be generated. The bracing system is helpful to prevent the frame from progressive collapse. The higher lateral stiffness of the frame can generate the smaller vertical deformation of the failed column at the restable position. However, the global failure temperature of the frame is not sensitive to the lateral stiffness of the frame.
\end{abstract}

KEYWORDS: Progressive Collapse, Steel Frame, Explicit Integration, Combined Analysis, Local Instability, Bracing system.

1,* PhD Research Student, Department of Civil and Structural Engineering, the University of Sheffield, Sheffield, S1 3JD, UK. Tel: +44-(0)114-2225726, Fax: +44-(0)114-2225700, Email: cip07rs@sheffield.ac.uk

${ }^{2}$ Reader, School of Engineering and Design, Brunel University, Uxbridge, Middlesex, UB8 3PH, UK.

3 Professor, Department of Civil and Structural Engineering, the University of Sheffield, Sheffield, S1 3JD, UK. 


\section{Introduction}

Structural engineers have a responsibility for incorporating fire safety into their building designs in order to minimize loss of life and property. The collapse of the twin towers of the World Trade Centre in New York was a reminder of the potential of fire to cause devastating failures of high-rise buildings by initiating progressive collapse. At present, steel structures have been widely used in the multi-story buildings because they are ideally suited to the current drive for improved construction efficiency as labour costs increase. However, the material properties of steel reduce significantly at elevated temperatures. For example, at $700^{\circ} \mathrm{C}$ the strength of steel is only $23 \%$ of ambient-temperature strength. At $800^{\circ} \mathrm{C}$ this has reduced to $11 \%$ and at $900^{\circ} \mathrm{C}$ to $6 \%$. Therefore, fire resistance design of steel buildings is a major concern to the structural engineers.

Currently, for structural fire engineering design, there is a trend that more designers will adopt the performance-based design approach. That means structures are treated integrally in structural fire safety design. For last two decades, extensive research has been carried out on the behaviour of steel-framed buildings under fire conditions. The Cardington full-scale fire tests [1] demonstrate that the real behaviour of structural elements can be very different from that indicated by standard furnace tests. In real buildings structural elements form part of a continuous assembly, and building fires often remain localized, with the fire-affected structure receiving significant restraint from cooler areas surrounding it. If such interactions are to be used by designers in specifying fire protection strategies as part of a performance-based structural design approach, then this cannot practically be based on large-scale testing because of the extremely high implicit costs. It is therefore becoming increasingly important that software models be developed to enable the behaviour of such structures to be predicted with sufficient accuracy under fire conditions. In recent years many researchers have developed numerical models to simulate the behaviour of steel or steel-composite frame in fire. For example, Wang and Moore [2] built a three dimensional model of a steel frame with semi-rigid connection to study the structural behaviour in fire. A computer program Vulcan has been developed at the University of Sheffield for three-dimensional modelling of steel, steel-framed composite and

reinforced concrete buildings in fire [3-7]. The computer program FEMFAN from the Fire 
Engineering Research Group at Nanyang Technological University has been used by Tan et al. [8-11], to study the behaviour of a number of steel frames under fire conditions. Franssen et al. [12] developed a computer program SAFIR, which was used by many researchers [13-15]. Also a number of researchers [16-24] used commercial FEA software ABAQUS to carry out the structural analysis of steel frames at elevated temperatures. The most of above mentioned analyses are based on static analysis. It is clear that static analysis is computational effective for modelling structural behaviour in fire in which the loading time is longer (from 0.5 to 4 hours). However, a shortcoming of static analysis is that the analyses would be terminated by numerical singularity or structural instability due to any localised members' failure.

Progressive collapse occurs when an initial local failure spreads from element to element, eventually resulting in collapse of a disproportionately large or entire part of a structure. Tan and Astaneh-Asl [25] experimentally studied the effective tying of steel structure subject to failure of key members and proposed a method to prevent progressive collapse using steel cables. Izzuddin et al. [26, 27] investigated the progressive collapse of multi-storey composite buildings modelled by a two-dimensional model. Liew [28] built a mix-element model to study three dimensional steel frames subject to blast load and fire attack. The model is capable of capturing detailed behaviour of member and frame instability associated with the effects of high-strain rate and fire temperature. Lien et al. [29] proposed the Vector Form Intrinsic Finite Element analysis of nonlinear behaviour of steel frame. They studied the behaviour of steel frame under fire induced by earthquake and concluded that the deformation of structure is significantly affected by the aftershock, fire and fracture of structural element.

The robustness of structure is the ability of the structure to prevent from disproportional failure after the local damage arisen by accidental actions. Hence, in order to assess of the robustness of structure in fire conditions, it is necessary to make sure that the analysis can go further after local instability taking place. Some researchers have tried to overcome this shortcoming of static analysis by carrying out full dynamic analysis for the whole duration of fire. Because the time of fire loading is relative long, hence the computation is very expansive. Therefore, the main objective of this paper is to develop a robust simplified numerical procedure in which the whole behaviour of a load-controlled structure can be modelled effectively. The model developed 
combines the static and dynamic analysis together to make full use of their advantages. Static analysis can be used to trace the behaviour of the structures at elevated temperature until the instability happened. After the instability of the analyses is identified, the dynamic procedure will be activated to continue the analysis. In this paper, an explicit dynamic procedure has been developed to allow modelling of the collapse of structural frames in fire. The model developed can be used to overcome the instabilities encountered in previous static analyses, and any restabilisation of the frame at high deflections can be identified. After the re-stabilisation of the frame gained the procedure will switch to static analysis again. The procedure developed was comprehensively validated. A series of parametric studies was conducted to investigate the mechanism of progressive collapse of planar steel frame due to the individual column failure.

\section{Non-linear procedure}

\subsection{Dynamic Procedure}

The general equation of a body motion can be expressed as:

$$
\boldsymbol{M} \ddot{\boldsymbol{u}}+\boldsymbol{C} \dot{\boldsymbol{u}}+\boldsymbol{F}(\boldsymbol{u})=\boldsymbol{Q}(t)
$$

Where $\boldsymbol{M}$ is the mass matrix, $\boldsymbol{C}$ is damping matrix, $\boldsymbol{F}(\boldsymbol{u})$ is the internal force vector and $\boldsymbol{Q}(t)$ is external force vector; $t, \mathbf{u}, \dot{\mathbf{u}}$ and $\ddot{\mathbf{u}}$ are time, displacement, velocity and acceleration vectors, respectively.

In order to solve Eq. (1) the direct-integration dynamic procedure provides two general operators: the implicit integration and explicit integration methods. In implicit dynamic analysis the integration operator matrix must be inverted and a set of nonlinear equilibrium equations must be solved at each time increment. But, for explicit one, no global mass or stiffness matrices need to be formed and inverted because displacements and velocities are calculated in terms of quantities that are known at the beginning of a time increment, thus, the calculation at each increment is relatively inexpensive compared to an implicit integration scheme.

Since implicit dynamic procedure requires forming and inverse the global stiffness matrix, hence, more disk space and memory are needed compared to explicit dynamic. Thus, for large scale problem explicit dynamic will be more effective than implicit one. Moreover, for problems with

high nonlinearity or material complexity, the implicit dynamic would have difficulty to get a 
converged solution, resulting in either a large number of iterations needed or numerical failure of the analysis. Since the high nonlinearity due to material degradation, failure of members and the local and global instability presented in the collapse of the structural frame, in this research explicit method is adopted as integration method for dynamic analysis.

\section{Time integration}

In the developed explicit dynamic procedure, central difference integration is used to integrate the equation of motion explicitly through the time, using the kinematic conditions at the current increment $i$ to calculate the kinematic conditions at the next increment, $i+1$. That is,

$$
\begin{gathered}
\dot{\boldsymbol{u}}_{i+1 / 2}^{n}=\dot{\boldsymbol{u}}_{i-1 / 2}^{n}+\Delta t_{i} \ddot{\boldsymbol{u}}_{i}^{n} \\
\boldsymbol{u}_{i+1}^{n}=\boldsymbol{u}_{i}^{n}+\Delta t_{i+1 / 2} \ddot{\boldsymbol{u}}_{i+1 / 2}^{n}
\end{gathered}
$$

Where $\boldsymbol{u}_{i}^{n}$ and $\dot{\boldsymbol{u}}_{i}^{n}$ are the displacement and velocity of degrees of freedom (DOF) $n$ at $i$-th time step, $\Delta t_{i}$ is the time step and the subscript $i$ refers to the current increment number of dynamic steps, $\Delta t_{i+1 / 2}=\left(\Delta t_{i}+\Delta t_{i+1}\right) / 2$. The key to the computational efficiency of the explicit

procedure is the use of diagonal elements of mass matrices because the acceleration at the beginning of the increment is computed by:

$$
\ddot{\boldsymbol{u}}_{i}^{n}=\left(\boldsymbol{M}^{n}\right)^{-1}\left(\boldsymbol{Q}_{i}^{n}-\boldsymbol{F}_{i}^{n}-\boldsymbol{D}_{i}^{n}\right)
$$

Where, $\ddot{\boldsymbol{u}}_{i}^{n}$ is the acceleration of DOF $n$ at $i$-th time step, $\boldsymbol{M}^{n}$ is the mass of DOF $n, \boldsymbol{Q}_{i}^{n}$ is the applied load, and $\boldsymbol{F}_{i}^{n}$ and $\boldsymbol{D}_{i}^{n}$ are the internal and damping force vectors, respectively. In this procedure the time increments must be quite small so that the accelerations are nearly constant during an increment. Since the time increments are small, analyses typically require many thousands of increments. Fortunately, each increment is computationally inexpensive because there are no simultaneous equations needed to be solved. Table 1 gives a summary and flowchart of the explicit dynamics algorithm developed.

\section{Mass matrix}


A robust beam-column element has been developed in Vulcan [4]. The cross section of the beam column is divided into a matrix of segments and each segment may have different material, temperature, and mechanical properties. For beam-column element in Vulcan (see Fig.1), the configuration of the beam is characterized using global coordinate $(x-y-z)$ and a local coordinate $\left(x^{\prime}-y^{\prime}-z z^{\prime}\right)$ which is located at the neutral axis of the beam. In this case, an effective way to form lumped mass matrix is to measure the translational displacements in global coordinates $(x-y-z)$, but to measure the angular velocity referenced to the natural coordinate.

The motion of the finite element model is described by the displacements $\boldsymbol{u}^{n, j}$, velocities $\dot{\boldsymbol{u}}^{n, j}$ and accelerations $\ddot{\boldsymbol{u}}^{n, j}$ of the node referenced to the global co-ordinate system ( $j=x, y, z$ and $n$ is the number of nodes). The rotational motion of the node is described by the angular velocities $\boldsymbol{w}^{n, j}$ and angular accelerations $\boldsymbol{\alpha}^{n, j}$. Let $\boldsymbol{F}^{n, x}, \boldsymbol{F}^{n, y}$ and $\boldsymbol{F}^{n, z}$ be the components of all internal nodal force in global co-ordinate system, let $\boldsymbol{Q}^{n, x}, \boldsymbol{Q}^{n, y}$ and $\boldsymbol{Q}^{n, z}$ be the components of all external nodal force in global co-ordinate system and let $\overline{\boldsymbol{F}}_{M}^{n, x}, \overline{\boldsymbol{F}}_{M}^{n, y}$ and $\overline{\boldsymbol{F}}_{M}^{n, z}$ be the corresponding moments, expressed in terms of the natural coordinate; and then, $\bar{Q}_{M}^{n, x}$, $\overline{\boldsymbol{Q}}_{M}^{n, y}$ and $\overline{\boldsymbol{Q}}_{M}^{n, z}$ be the corresponding external applied moments, expressed in terms of the natural coordinate. Hence, translational equations of the motion of the node $n$ are:

$$
\boldsymbol{M}^{n} \ddot{\boldsymbol{u}}^{n, j}=\left(\boldsymbol{Q}^{n, j}-\boldsymbol{F}^{n, j}\right)(i=x, y, z)
$$

Here, $\boldsymbol{M}^{n}$ is the translational mass at the node $n$ in global coordinate. Then rotational equations of the motion of the node $n$ in nodal co-ordinate system are the usual Euler Equation [30]:

$$
\begin{aligned}
& \boldsymbol{I}^{n, x x} \overline{\boldsymbol{\alpha}}^{n, x}+\left(\boldsymbol{I}^{n, z z}-\boldsymbol{I}^{n, y y}\right) \overline{\boldsymbol{w}}^{n, y} \overline{\boldsymbol{w}}^{n, z}=\overline{\boldsymbol{Q}}_{M}^{n, x}-\overline{\boldsymbol{F}}_{M}^{n, x} \\
& \boldsymbol{I}^{n, y y} \overline{\boldsymbol{\alpha}}^{n, y}+\left(\boldsymbol{I}^{n, x x}-\boldsymbol{I}^{n, z z}\right) \overline{\boldsymbol{w}}^{n, z} \overline{\boldsymbol{w}}^{n, x}=\overline{\boldsymbol{Q}}_{M}^{n, y}-\overline{\boldsymbol{F}}_{M}^{n, y} \\
& \boldsymbol{I}^{n, z z} \overline{\boldsymbol{\alpha}}^{n, z}+\left(\boldsymbol{I}^{n, y y}-\boldsymbol{I}^{n, x x}\right) \overline{\boldsymbol{w}}^{n, x} \overline{\boldsymbol{w}}^{n, y}=\overline{\boldsymbol{Q}}_{M}^{n, z}-\overline{\boldsymbol{F}}_{M}^{n, z}
\end{aligned}
$$

Where $\boldsymbol{I}^{n, x x}, \boldsymbol{I}^{n, y y}$ and $\boldsymbol{I}^{n, z z}$ are the principal moments of inertia for node $n, \overline{\boldsymbol{\alpha}}^{n, y}, \overline{\boldsymbol{\alpha}}^{n, y}, \overline{\boldsymbol{\alpha}}^{n, z}$ and $\overline{\boldsymbol{w}}^{n, x}, \overline{\boldsymbol{w}}^{n, y}, \overline{\boldsymbol{w}}^{n, z}$ are angular accelerations and velocities, respectively. The above expressions about the rotational equations of motion are not well suited for an explicit finite element code because they are nonlinear in term of $w$ and not easy to integrate with time. Thus, it is assumed 
that the nodal rotational inertia is homogeneous for a node. The simplification made results in a simper set of equations for rotational motion in global coordinates as:

$$
\begin{aligned}
& \boldsymbol{I}^{n, x x} \overline{\boldsymbol{\alpha}}^{n, x}=\overline{\boldsymbol{Q}}_{M}^{n, x}-\overline{\boldsymbol{F}}_{M}^{n, x} \\
& \boldsymbol{I}^{n, y y} \overline{\boldsymbol{\alpha}}^{n, y}=\overline{\boldsymbol{Q}}_{M}^{n, y}-\overline{\boldsymbol{F}}_{M}^{n, y} \\
& \boldsymbol{I}^{n, z z} \overline{\boldsymbol{\alpha}}^{n, z}=\overline{\boldsymbol{Q}}_{M}^{n, z}-\overline{\boldsymbol{F}}_{M}^{n, z}
\end{aligned}
$$

The above equation can also be expressed as:

$$
\begin{aligned}
& \boldsymbol{I}^{n, x x} \boldsymbol{\alpha}^{n, x}=\boldsymbol{Q}_{M}^{n, x}-\boldsymbol{F}_{M}^{n, x} \\
& \boldsymbol{I}^{n, y y} \boldsymbol{\alpha}^{n, y}=\boldsymbol{Q}_{M}^{n, y}-\boldsymbol{F}_{M}^{n, y} \\
& \boldsymbol{I}^{n, z z} \boldsymbol{\alpha}^{n, z}=\boldsymbol{Q}_{M}^{n, z}-\boldsymbol{F}_{M}^{n, z}
\end{aligned}
$$

The inertia properties of the beam-column element are lumped by the following procedure:

(1) Element translational mass matrix:

The consistent mass matrices are given by the relationship:

$$
\boldsymbol{M}^{e}=\int_{V}[\boldsymbol{N}]^{T} \rho[\boldsymbol{N}] d V
$$

where $\rho$ is the density of the element material and $[\boldsymbol{N}]$ is the shape function matrix. The lumped procedure adopted here, which is called 'Consistent Diagonal Lumping' or 'HRZ' method, is based on the consistent mass matrix. The diagonal coefficient of consistent mass matrix associated with translational DOFs $\boldsymbol{M}_{1, j}^{e}, \boldsymbol{M}_{2, j}^{e}$, and $\boldsymbol{M}_{3, j}^{e} \cdot(j=x, y, z)$ can be computed as:

(a) Compute total mass of element, $m$;

(b) Compute $s$ by adding diagonal coefficients associated with translational DOFs that are in the same direction: $s=\boldsymbol{M}_{1, j}^{e}+\boldsymbol{M}_{2, j}^{e}+\boldsymbol{M}_{3, j}^{e}$;

(c) Scale all diagonal coefficients obtained in (a) by multiplying them with $\mathrm{m} / \mathrm{s}$ :

$$
\boldsymbol{M}_{1, j}^{e, \text { lump }}=\boldsymbol{M}_{1, j}^{e} \times m / s, \boldsymbol{M}_{2, j}^{e, \text { lump }}=\boldsymbol{M}_{2, j}^{e} \times \frac{m}{s} \text { and } \boldsymbol{M}_{3, j}^{e, l u m p}=\boldsymbol{M}_{3, j}^{e} \times m / s ;
$$

(2) Element rotational mass:

Nodal mass moments about all three axes are assumed to be the same and calculated as:

$$
\begin{aligned}
m & =\sum_{J=1}^{N s e g} \rho_{J} l A \\
I_{1} & =\frac{m l^{2}}{12}+\sum_{J=1}^{N s e g} \rho_{J} l I_{y y}
\end{aligned}
$$




$$
\begin{aligned}
& I_{2}=\frac{m l^{2}}{12}+\sum_{J=1}^{N s e g} \rho_{J} l I_{z z} \\
& I_{3}=2 \sum_{J=1}^{N s e g} \rho_{J} l I_{x x} \\
& I_{R}=\max \left(I_{1}, I_{2}, I_{3}\right) \\
& I_{n}=\mu \cdot I_{R}
\end{aligned}
$$

Where $A=$ element cross section area, $l=$ element length, $m=$ element mass, $I_{x x}, I_{y y}, I_{z z}=$ cross section moments of inertia, $\rho_{J}=$ material density of $J$-th segment, $I_{n}=$ mass moment lumped to node $n, N$ seg is the total number of segments of cross section and $\mu$ is associated to the ratio between the mass lumped on each node with the total mass of the element.

\section{Damping matrix}

Damping in nature comes from various mechanisms. Its effect on structural response is to cause the displacement amplitude to decay with time (dissipation of energy). In general, for the analyses of structures, damping is assumed to be viscous or velocity-proportional for the ease of solution. In the current study, a mass proportional damping matrix is assumed.

$$
\mathbf{C}=\beta \cdot \mathbf{M}
$$

Where, $\beta=2 \xi \varpi_{i} \varpi_{j} /\left(\varpi_{i}+\varpi_{j}\right)$, $\xi$ is the damping ratio, $\mathbf{M}$ is the mass matrix, $\varpi_{i}$ and $\varpi_{j}$ are the frequencies of the $i$ and $j$-th modes, respectively.

\section{Limitation of time step size}

Taking the nonlinearity and damping into accounting, the estimation of the stable time step limit $\Delta t$ for Beam-Column element in this procedure is:

$$
\Delta t=\mu\left(\frac{L}{c_{p}}\right)\left(\sqrt{\xi^{2}+1}-\xi\right)
$$

Where $L$ is the element length, $\xi$ is the damping ratio and $\mu$ is the reduction factor for nonlinear system (normally, $\mu=0.4-0.8$ based on experience).

$$
C_{p}=\sqrt{\frac{E_{n}(1-v)}{(1+v)(1-2 v) \rho_{n}}}
$$

where $E_{n}$ is the Young's modulus of segment, $\rho_{n}$ is the density of segment, $v$ is Poisson ratio. 


\section{Energy balance check}

In order to discern the instable solution, the energy balance check is also developed in this procedure. The instable solution can be easily detected by energy balance check as any instability would result in the spurious generation of energy which leads to a violation of the conservation of energy. Therefore, the maintenance of stability can be established by checking the energy balance.

In central difference method, the energy $W$ is usually integrated in time by a trapezoidal rule. The external, internal, kinetic and damping dissipated energy are given by:

$$
\begin{aligned}
& W_{\text {int }}^{n+1}=W_{\text {int }}^{n}+\frac{1}{2} \Delta \boldsymbol{u}^{T}\left(\boldsymbol{F}_{\text {int }}^{n}+\boldsymbol{F}_{\text {int }}^{n+1}\right) \\
& W_{\text {ext }}^{n+1}=W_{\text {ext }}^{n}+\frac{1}{2} \Delta \boldsymbol{u}^{T}\left(\boldsymbol{Q}_{\text {ext }}^{n}+\boldsymbol{Q}_{\text {ext }}^{n+1}\right) \\
& W_{\text {kin }}^{n}=\frac{1}{2} \boldsymbol{u}^{T} \boldsymbol{M u}
\end{aligned}
$$

Here, $F_{i n t}^{n}$ and $Q_{e x t}^{n}$ represents the internal and external force at $n$-th time step. The energy conservation requires that

$$
\left|W_{\text {int }}+W_{\text {kin }}-W_{\text {ext }}\right| \leq \varphi \max \left(W_{\text {int }}, W_{\text {kin }}, W_{\text {ext }}\right)
$$

Where $\varphi$ is a small tolerance, generally on the order of $10^{-2}$ ( 0.05 used here).

\subsection{Combined static-dynamic procedure}

In this paper a robust combined static-dynamic procedure has been developed to model stable and unstable parts of the structural analysis in fire. Table 2 shows the flowchart of the developed combined procedure. Compared to full dynamic procedure the static analysis is computationally effective when the analyzed structure is stable at elevated temperatures. Normally, the structural members are subjected to constant loads under fire conditions. Due to the degradation of the materials at elevated temperatures the load capacity of the member is reduced with temperatures increasing. At certain temperature when the load capacity of the certain members is less than the load applied on them, the failure of the members will occur to initiate the local or global collapses of the structure.

As shown in Table 2, once the stability of the structures is lost, the dynamic procedure can be switched on automatically and the analysis can be carried on. It is assumed that the switch 
between static and dynamic analysis happens within a single temperature increment step. As described above, the explicit scheme is adopted in the dynamic procedure. The internal energy, external energy and kinetic energy are calculated at each step. The criterion for switching on the dynamic analysis is that the convergence of the static analysis fails to be found; while the switch from dynamic analysis back to static analysis depends on the kinetic energy of the structure. If the increase of kinetic energy is relative small compared to the internal energy, which means that the velocity of structural members' movement becomes very small, the stability of analyzed structure might be achieved. If the stability of the structure is regained during the analysis, the static procedure is triggered once again. The analysis will be kept going until the final global failure of structure.

Obviously, the proposed static-dynamic procedure has many advantages against other methods. Compared with previous static analysis, the proposed procedure has extended ability to trace the structural behavior from local failure to final global collapse. This is very important for evaluating the robustness of structure against progress collapse under fire conditions. However, compared with traditional full dynamic analysis, the developed procedure has the advantage to reduce computational time significantly. Since the heating of structures in fire is a slow timedependant process and the time step of dynamic analysis is normally small in order to guarantee the converge results. Hence, it is quite expansive in term of computational time for using full dynamic analysis to simulate structural behavior under fire loads. With proposed static-dynamic procedure, the structural behavior at elevated temperatures is mainly simulated by static analysis. Only when the temporary instability of the analyzed structure happens then the dynamic timehistory analysis will be triggered. This will improve the computational efficiency dramatically. The quantitive comparisons will be demonstrated in the following validation section.

\section{Validation}

\subsection{Elastic vibration test}

A forced vibration of simply supported beam as shown in Fig. 2 was analyzed. A concentrated load was applied at the mid-span of the beam with the time-force curve which is shown in Fig. 3. The cross section of the beam as shown in the Fig. 2 was adopted. Linear elastic material 
properties with Young's modulus, $E=205000 \mathrm{MPa}$, was assumed. Eight elements were used to model this beam. In the analysis the time step was automatically estimated. The predicted midspan displacements against time are presented in Fig. 4 together with the results generated by ABAQUS and Close-form solution which was based on the elastic vibration theory. It is evident that the results by three methods are in good agreement.

\subsection{Stability problem}

The Williams toggle frame [31], as shown in Fig. 5, has the structural behaviour of snap-through buckling and its results have been used for verification of numerical solutions by many researchers. The structure was assumed to be elastic and the material properties as indicated in Fig. 5 were used. The fixed bases and rigid connection at apex were assumed. The concentrated load at apex point of frame was increasing at a constant rate with time. At force level around $150 \mathrm{~N}$ the snap-trough happened. The frame dropped rapidly and returned to the stable position again later.

Fig. 6 shows the comparison of the load-displacement relationships obtained by the current model and numerical results predicted by Yang and Chiou [32], together with the test results of the Williams [31]. It is evident that the developed dynamic procedure can accurately handle this problem.

\subsection{Steel frames tested in fire}

The model has been validated using data from two groups of steel frames, tested by Rubert and Schaumann [33] and subsequently investigated by other researchers [34, 35]. The structural details are shown in Fig.7. The frames were all uniformly heated by ISO834 standard fire. The L-shaped frame was designated as EHR, and the double-span one was designated as ZSR as shown in Fig.7. All structural elements were made of IPE80 I-sections. The comparisons of predicted displacements at different locations within the frames against the temperature are shown in Fig. 8, together with the tested results [33] and other models' predictions [34, 35]. It can be seen that the results generated by the current model agreed well with the tested data and the predictions from other models.

\subsection{Instability problem in fire}


To validate the combined static-dynamic procedures developed, the simple frame as shown in Fig. 9 has been investigated under ISO843 fire. The frame was also analyzed using the commercial software ABAQUS/Standard to validate the current model. In this case implicit integration was used in the ABAQUS full dynamic model. In the current procedure, the dynamic analysis is switched on when the static analysis terminates as the instability of frame takes place; then when the re-stable position is regained, the static procedure is restarted to carry on the analysis. As indicated in Fig. 10, results generated by the current model agree well with the predictions from ABAQUS. It is evident that current combined procedure is capable to trace the behaviour of structure after local failure (snap-through, etc.) occurs and the analysis can be continued up to the total failure of structure.

For considering the computational efficiency, it is difficult to make a direct comparison between the different computer programs due to the different FE formulations adopted in the programs. Therefore, above case has been analysed again by using full dynamic procedure developed in this paper. In full dynamic analysis the computing time needed is proportional to fire duration. Hence, if the real fire time, such as $60 \mathrm{~min}$, is adopted for the analysis the massive computing time is required to finish the modelling. However, it is often possible to scale the real time to a very small equivalent time period if the response of the structure in fire remains basically static. In order to save the computational time, the 60 -min standard fire is scaled down to 20 s for full dynamic simulation. Almost identical results were produced for both full dynamic and combined static-dynamic analyses. For this case the computing times for full dynamic and combined static-dynamic procedures were $15 \mathrm{~min}$ and $60 \mathrm{~min}$, respectively by using the same computer. This indicates that the computational efficiency is improved significantly by suing current combined static-dynamic procedure.

\section{Case studies}

In order to demonstrate the capability of the developed procedure a series parametric analyses was conducted. Firstly, a uniformly heated latticed frame was modelled. Followed, a 2D three stores with 4 bays steel frame has been investigated.

\subsection{Truss frame in fire}


Fig. 11 shows the details of the truss frame analysed in this study. All members of frame were assumed to be heated by ISO834 standard fire. In the analyses two different cases with rigid and pinned column bases were modelled. The vertical displacements at the apex of the frame against temperature for different support conditions are shown in Fig. 12. It can be seen that the structure experienced extremely large bending during the deformation. Also, the case with rigid column based can re-stabilize after initial lost of the stability of the frame. However, there was no restabilised point for the case with pin column base. The collapse mechanisms of the two cases differ due to the different boundary conditions, even though the critical collapse temperature does not change too much. For the rigid-based frame the failure was initiated by member buckling at the location A as shown in Fig 13; however, the failure began at the locations B and $\mathrm{C}$ in the pin-based frame. This case study indicates that the ability of the developed procedure can handle the high nonlinearity and large deflection problems with very good computational efficiency.

\subsection{D steel frames at elevated temperatures}

Results from previous research works including the large scale fire test at BRE's Cardington laboratory suggest that although it is now possible to eliminate fire protection to some steel beams without compromising its overall structural fire resistance safety. However, the steel columns are critical members and their behaviour affects the overall stability of the frame. The failure of column is definitely a typical source to generate collapse of frame. Thus, the collapse mechanism of the buildings after column failure happened should be properly and clearly understood in order to design the frame against total collapse of the structures under fire conditions.

In this study the mechanism of the frame collapse due to the failure of the individual column was investigated. As part of a complete structure, the behaviour of column is affected by the adjacent structural members and also the column can interact with the adjacent structure in many ways. After one or several columns fail, the force supported by the failed column will be redistributed to the surrounding structural members. If the surrounding structural members are strong enough to support those forces, the tendency of progressive collapse of the structures would be stopped. Otherwise, the local failure of the substructure would spread to other part of structure and 
generate global collapse of the buildings. The study conducted here demonstrates the robustness of the current combined static-dynamic procedure.

\subsubsection{One column failure}

A preliminary study of the frame with only one column heated to failure was carried out. It gives fundamental insight of the loading redistribution mechanism and the members' interaction within a steel frame. As shown in Fig. 14, a 3 story and 4 bay frames with UB $305 \times 165 \times 54$ beam section and UC $254 \times 254 \times 73$ column section was analyzed. The middle column C1 was assumed to be heated by standard fire and the rest of the frame remained as ambient temperature. European steel profiles of S235 steel grade was adopted and all beam-to-column connections were considered to be rigid.

In the column $\mathrm{C} 1$ as the temperature rising, additional compression force was generated due to the thermal expansion and the restraint provided by the surrounding cool structure. The material strength of the steel was also degraded as temperature elevating. When the compression force within the column exceeded the buckling load of the column $\mathrm{C}$, the buckle of the column took place. After the buckle of the column the loads supported by the column $\mathrm{C} 1$ were re-distributed to the adjacent remaining structural members. Fig. 15 shows the failure mode of the frame studied and the development of the plastic hinges at the different stages.

It is clear that the restraints to the column are mainly provided by the beams above the heated column. In order to investigate the influence of the restraints on the columns to the frame behaviour, the analyses were repeated by using different beam sections for the frame. The vertical displacements at the top of the heated column with different beam section sizes are shown in Fig. 16. Since different beam sections provide different stiffness and strength, hence the beam section not only influences the critical temperature of column but also affect the loading sharing mechanism of the frame. Fig. 17 shows the axial forces of the columns $\mathrm{C} 1$ and C2 against temperature for using different beam sizes. Form the Fig. 17(a) it is clear that at the same temperature level the big size of the beam generated lager additional compressive force in the column $\mathrm{C} 1$. Therefore, the temperature level at which the column $\mathrm{C} 1$ starts to buckle is lower for the large beam compared to the small beam. However, due to the rigid connection assumed between the beam and column when the column $\mathrm{C} 1$ gradually lose it strength the beam behaves 
like a continue beam over the column $\mathrm{C} 1$. Hence, big beam can resist more bending moment which is resulted due to the losing support capacity of the column C1. Fig. 17(b) shows the different vertical loads transferred to the column $\mathrm{C} 2$ for different beam sizes. It is clear that after the heated column $\mathrm{C} 1$ fails, the force taken by the column was redistributed. Hence, the axial force acting on the column $\mathrm{C} 2$ increased. Also, using bigger beam section increases the possibility of re-stabilization after the failure of the column.

The failure process of the frame as shown in Figs. 15(c) and (d) indicates that the plastic hinges firstly generate in the middle bay; then spread to the edge bays. With increasing the size of the beam section, the lateral stiffness of edge span is getting stronger. When the lateral stiffness is big enough to hold the catenary force generated in the beam, the frame can be re-stabilized eventually and failure stage II disappears. It is evident that increasing beam section can prevent the frame from totally collapse when one column fails. Also the lateral support of the frame can enhance the capacity of the frame to avoid the progressive collapse.

The force in joints connecting to the failed column is another interesting topic. As shown in Fig. 18, the axial forces of connections change after column failure. That is because the failure of middle column $\mathrm{C} 1$ would generate large deformation of beam, and then catenary action would developed in the connected beams to hold the redistributed force. As shown in Fig.18, the force in connection J1 in the same floor as failed column (see Fig. 14) changes significantly from $80 \mathrm{KN}$ to $680 \mathrm{KN}$ after the column $\mathrm{C} 1$ failed. This means that the catenary action is significantly developed in the beams which connect to the failed column. The axial forces in the connections $\mathrm{J} 2$ and $\mathrm{J} 3$ were also changed as shown in the figure. However, compared to the connection J1 these changes are insignificant. Therefore, for the design with the purpose of preventing frame collapse, the connections in the same floor with the failed column should be under specially attention.

\subsubsection{Progressive column failure}

In a real fire, several columns can be heated at the same time. When one column fails as a source of collapse, the other columns would be more vulnerable because their strength degrades as the fire develops. In this case, the columns will fail progressively, which will induce the total collapse of the frame. As shown in Fig. 19, a 4 story- 4 bay frames was considered in this case 
study. All columns in the ground floor were heated by standard fire, but the middle column C1 had higher temperature $\left(300^{\circ} \mathrm{C}\right.$ higher) so this column was the source column of collapse. The temperature-time curves of the heated columns are shown in Fig.20. The behaviour of frame under this scenario has been investigated and influences of different parameters were investigated.

\section{Influence of the loadings}

Frame analyses with different loading ratios of column $(0.3,0.5$ and 0.73$)$ were carried out. With increasing loading ratio, the failure temperature of column decrease (see Fig. 21). There was no sign of re-stabilization for these three loading ratios. Fig. 22 shows the axial forces of the columns C2 against temperature for using different loadings. As shown in Fig. 23 the collapse mechanism of the frame changes with the loading ratio. For higher loading ratios (see Fig. 23(a)), the source column $\mathrm{C} 1$ buckled at relative low temperature, in which the rest columns did not buckle, although they were heated. The total collapse of frame (failure mode I) in this case was due to the lack of lateral support. With lower loading ratio, the frame could stand for more time with higher failure temperature. However, when the source column $\mathrm{C} 1$ failed, then the loads were transferred to the other columns. Due to the other columns were heated as well hence the buckling took place in all rest columns. The failure mode of this case was presented in Fig. 23(b). It can be seen that the failure mode II of the frame is more destructive compared to the failure mode I.

\section{Influence of beam sections}

The analyses conducted in Section 4.2.1 indicate that the different collapse mechanism of the frame could be generated by using different beam sections. Hence, three beam sections of UB356×171×57 (UB1), UB406×178×74 (UB2) and UB686×254×170(UB3) were employed in this study. Fig. 24 presents the comparison of the vertical displacements at the top of the column $\mathrm{C} 1$ for using different beam sections. It is clear that the bigger beam section which can provides

stiffer lateral restraints could make the frame stood up longer time with higher failure temperature. Fig. 25 shows the axial forces of the columns C2 against temperature for using 
different beam sections. The different collapse mechanisms of the frame with different beam sizes are shown in Fig. 26.

For the case with beam section UB $356 \times 171 \times 57$, due to the buckling of source column $\mathrm{C} 1$ the

substructure in middle spans was significantly deformed downward, and the plastic hinges developed in the beam section of middle spans. The vertical force of the failed column $\mathrm{C} 1$ was distributed to the neighbouring columns, such as column C2 (see Fig. 25). Moreover, the catenary forces in the beams within the mid span of the frame increased significantly due to the large deformations. When the lateral support of the frame was not strong enough to carry the huge catenary forces in the beams then the failure mode of the frame was generated as shown in Fig. 26(a).

For the case with beam section UB $406 \times 178 \times 74$, after the buckling of column C1, column C2 could not take the force transferred from $\mathrm{C} 1$ and buckled as well. Fig. 26(b) shows the failure mode of this case. For case with beam section UB $686 \times 254 \times 170$, after the buckling of column $\mathrm{C} 1$, the frame above the ground floor is so stiff and strong that the load taken by $\mathrm{C} 1$ could all redistribute to the surrounding columns. Moreover, the temperature of neighbouring columns was higher compared to the previous two cases when the source column $\mathrm{C} 1$ buckled. Hence, all adjacent columns within the ground floor buckled simultaneously and the frame failed as shown in Fig. 26 (c).

\section{Influence of bracing system}

As discussed above, the lateral support plays an important part in preventing the frame from the global collapse. All cases analysed above in the un-braced 2D frame there were no re-stabilized positions gained after some members failed or buckled. In order to study the effective way for preventing the frame from collapse, the influence of lateral bracing system was investigated. The bracing system was modelled by axial elastic spring with different stiffness as shown in Fig. 27. In this study the bracing systems with different lateral stiffness were investigated. The stiffness of each spring for the story was determined by push-over analysis. The lateral stiffness ratio is defined as:

$$
\mu=K_{b} /_{K_{s}}
$$


where $K_{b}$ is the lateral stiffness of bracing and $K_{s}$ is the story stiffness of the frame. The vertical displacements at the top of the column $\mathrm{C} 1$ for using different lateral stiffness ratios are presented in Fig. 28. Fig. 29 shows the axial forces of the columns C2 against temperature for using different lateral stiffness ratios.

It can be seen that the influence of the lateral restraint on the deformation of the frame is very significant. Re-stabilized of the frame can be achieved by provided only small lateral restraint such as $\mu=0.1$. It is interesting that the global failure of the frame is not sensitive to the different values of the lateral stiffness. In this case the global failure temperature of the frame is about $860{ }^{0} \mathrm{C}$ for $\mu=0.1$ to $\mu=\infty$. This is because of when the certain lateral stiffness provided for the frame the global failure of the structure is caused by the progress failure of the columns within that floor. This can be further proved by the failure process of the braced frame as shown in Fig. 30.

The forces in connection J1 (see Fig. 27) which connected to the column C1 has been compared. The results for three typical frames with $\mu=0.1, \mu=1.0$, and $\mu=10$ are presented in Fig. 31 . It is shown that two big jumps appeared in the connection axial force against temperature curves. The first jump in the curve was happened when buckling of column C1 took place. It can be seen that the lateral stiffness of bracing system doesn't have significant effect on the axial force generated in the connection $\mathrm{J} 1$ when buckling of source column $\mathrm{C} 1$ occurs at about $760{ }^{0} \mathrm{C}$. Then with increasing of temperature, the other columns soften and the axial force in the connection increases. It is observed that the stiffer lateral bracing system can provide larger axial force in connection after source column $\mathrm{C} 1$ buckles.

\section{Conclusions}

In this paper a robust combined static-dynamic procedure has been developed. In this model the numerical singularity induced by local or temporary instability of structure can be overcome by introducing dynamic analysis. The procedure with effective switch between static and dynamic analysis is a powerful tool to trace the progressive collapse of structure under fire conditions. The developed procedure has been comprehensively validated against the results generated from the previous researches and using some commercial software. 
A series of case studies has been conducted in order to deeply understand the collapse mechanism of structures under different fire scenario. Different parameters including the influences of loading ratio, beam section and bracing systems has been studied. The results show that for un-braced frame the different loading ratio and beam section can generate different collapse mechanisms. The lower loading ratio and bigger beam section can give higher failure temperature in which the global collapse of the frame happened. However, the higher loading ratio and smaller beam section can more easily to generate localised collapse. The bracing system is helpful to prevent the frame from progressive collapse. The higher lateral stiffness can generate the smaller vertical deformation of failed column at re-stable position. But the global failure temperature of the frame is not sensitive to the lateral stiffness of the frame. The axial force in the connections jointed to the failure column should be paid special attention in design and the stiffer lateral system can generates larger axial force in the connections.

\section{References:}

[1] Building Research Establishment, Client Report: Results and Observations from Full-Scale Fire Test at BRE Cardington, 16 January 2003.

[2] Y.C. Wang and D.B. Moore, Steel frames in fire: Analysis, Engineering Structure 17 (6) (1995), pp. 462-472.

[3] Yu, X.M. and Huang, Z., "An embedded FE model for modelling reinforced concrete slabs in fire”, Engineering Structures, 30 (11), 2008, pp 3228-3238.

[4] Huang Z, Burgess IW and Plank RJ "Three-dimensional analysis of reinforced concrete beam-column structures in fire. Journal of Structural Engineering, ASCE, 135 (10), 2009, pp 1201-1212.

[5] Yu, C., Huang, Z., Burgess, I.W. and Plank, R.J., "Development and validation of 3D composite structural elements at elevated temperatures", Journal of Structural Engineering, ASCE, 136 (3), 2010, pp275-284.

[6] Huang, Z., "Modelling of reinforced concrete structures in fire", Proceedings of the Institution of Civil Engineers Journal, Engineering and Computational Mechanics, 163(EM1), 2010, pp43-53.

[7] Huang, Z., "Modelling the bond between concrete and reinforcing steel in a fire", Engineering Structures, 32 (11), 2010, pp 3660-3669.

[8] K.H. Tan, S.K. Ting and Z.F. Huang, Visco-elasto-plastic analysis of steel frames in fire, J Struct Eng ASCE 128 (1) (2002), pp. 105-114.

[9] Z.F. Huang and K.H. Tan, Effects of external bending moments and heating schemes on the responses of thermally restrained steel columns, Engineering Structure 26 (2004), pp. 769-780. 
[10] Z.F. Huang and K.H. Tan, Structural responses of axially restrained steel beams with semirigid moment connection in fire, J Struct Eng ASCE 131 (4) (2005), pp. 541-551.

[11] Z.F. Huang, K.H. Tan and S.K. Ting, Heating rate and boundary restraint effects on fire resistance of steel columns with creep, Engineering Structure 28 (2006), pp. 805-817.

[12] Franssen JM, Kodur VK, Mason J. User's manual for SAFIR 2001: A computer program for analysis of structures submitted to the fire. Belgium University of Liege, 2002.

[13] R. Becker, Structural behaviour of simple steel structures with non-uniform longitudinal temperature distributions under fire conditions, Fire Safety J 37 (2002), pp. 495-515.

[14] V. Souza Junior and G.J. Creus, Simplified elastoplastic analysis of general frames on fire, Engineering Structure 29 (2007), pp. 511-518.

[15] A. Buchanan, P. Moss, J. Seputro and R. Welsh, The effect of stress-strain relationships on the fire performance of steel beams, Engineering Structure 26 (2004), pp. 1505-1515.

[16] A.M. Sanad, J.M. Rotter, A.S. Usmani and M.A. O'Connor, Composite beams in large buildings under fire: Numerical modelling and structural behaviour, Fire Safety J 35 (3) (2000), pp. 165-188.

[17] Y.Z. Yin and Y.C. Wang, A numerical study of large deflection behaviour of restrained steel beams at elevated temperatures, J Construct Steel Res 60 (2004), pp. 1029-1047.

[18] H. Chen and J.Y.R. Liew, Explosion and fire analysis of steel frames using mixed element approach, Journal of Engineering Mechanics ASCE 131 (6) (2005), pp. 606-616.

[19] K.T. Ng and L. Gardner, Buckling of stainless steel columns and beams in fire, Engineering Structure 29 (2007), pp. 711-730.

[20] J. Chen and B. Young, Cold-formed steel lipped channel columns at elevated temperatures, Engineering Structure 29 (2007), pp. 2445-2456.

[21] J.B.P. Lim and B. Young, Effects of elevated temperatures on bolted moment-connections between cold-formed steel members, Engineering Structure 29 (2007), pp. 2419-2427.

[22] J.A. El-Rimawi, I.W. Burgess and R.J. Plank, Studies of the behavior of steel subframes with semi-rigid connections in fire, J Construct Steel Res 49 (1999), pp. 83-98.

[23] J.C. Zhao, Application of the direct iteration method for non-linear analysis of steel frames in fire, Fire Safety J 35 (2000), pp. 241-255.

[24] A. Landesmann, E.M. Batista and J.L.D. Alves, Implementation of advanced analysis method for steel-framed structures under fire conditions, Fire Safety J 40 (2005), pp. 339366.

[25] Samuel Tan, Albolhassan Astaneh-Asl. Cable-based retrofit of steel building floors to prevent progressive collapse. Berkeley: University of California; 2003.

[26] B.A. Izzuddin et al., Progressive collapse of multi-storey buildings due to sudden column loss_Part I: Simplified assessment framework, Engineering Structures 30 (2008), pp. 1308-1318.

[27] .A. Izzuddin et al., Progressive collapse of multi-storey buildings due to sudden column loss-Part II: Simplified assessment framework, Engineering Structures 30 (2008), pp. 1424-1438.

[28] J.Y.R. Liew, Survivability of steel frame structures subject to blast and fire, Journal of Constructional Steel Research 64 (7-8) (2008), pp. 854-866. 
[29] K.H. Lien et al., Vector Form Intrinsic Finite Element analysis of nonlinear behavior of steel structures exposed to fire. Engineering Structure 32 (2010), pp. 80-92.

[30] R. Vignjevic, A hybrid approach to the transient collapse analysis of thin walled frameworks I. Comput. Methods Appl. Mech. Eng. 148 (1997), pp. 407-421.

[31] Williams, F.W. (1964). "An Approach to the Non-linear Behavior of the Members of a Rigid Jointed Plane Framework with Finite Deflections.” Quart. J. Mech. Appl.Math., Vol. 17, 451-469.

[32] Y.B. Yang and H.T. Chiou, Rigid body motion test for nonlinear analysis with beam elements, ASCE J.Engrg. Mech. 113 (9) (1987) 1404-1419.

[33] Rubert and Schaumann Rubert A, Schaumann P. Structural steel and plane frame assemblies under fire action. Fire Safety Journal 1986;10:173-84.

[34] K.H. Lien K H Lien, Y J Chiou. Vector form intrinsic finite element analysis of nonlinear behaviour of steel structure exposed to fire. Engineering Structure. 32(2010) Pages 80 - 92.

[35] Ali Hosam M. Ali, Lateral displacement and collapse of single-story steel frames in uncontrolled fires. Engineering structure. 26(2004) PP. 593-607. 


\section{Figure Captions}

Fig. 1. Three dimensional 3-noded beam-column element configurations.

Fig. 2. A forced vibration of simply supported beam.

Fig. 3. Load-time curve.

Fig. 4. Comparisons of predicted mid-span displacements against time for the three procedures.

Fig. 5. Williams toggle frame [31].

Fig. 6. Comparisons of predicted vertical displacement at apex with test results.

Fig. 7. Tested steel frames in fire [33]: (a) EHR frame; (b) ZSR frame.

Fig. 8. The comparisons of predicted and tested displacements at different locations within the frames.

Fig. 9. The details of studied steel frame in fire.

Fig. 10. Comparison of the predicted vertical displacement U1 by using different models.

Fig. 11. The details of the analysed truss frame in fire.

Fig. 12. The vertical displacement at the apex of the frame against temperature.

Fig. 13. The failure process of the truss frame for different column base conditions in fire.

Fig. 14. Details of 2D steel frame with one column heated.

Fig. 15. The failure modes and the development of the plastic hinges for the studied frame.

Fig. 16. Comparison of the vertical displacements at the top of the column $\mathrm{C} 1$ for using different beam sizes.

Fig. 17. The axial forces of the columns $\mathrm{C} 1$ and $\mathrm{C} 2$ against temperature for using different beam sizes.

Fig. 18. The axial forces in the connections $\mathrm{J} 1, \mathrm{~J} 2$ and $\mathrm{J} 3$ against temperature.

Fig. 19. Details of 2D steel frame with several columns heated.

Fig. 20. Temperatures against time for the heated columns.

Fig. 21. Comparison of the vertical displacements at the top of the column $\mathrm{C} 1$ for using different loadings. 
Fig. 22. The axial forces of the columns $\mathrm{C} 2$ against temperature for using different loadings.

Fig. 23. The failure modes for the studied frame with different loadings: (a) Failure mode I (loading ratio $=0.75$ and 0.5 ); (b) Failure mode II (loading ration $=0.3$ ).

Fig. 24. Comparison of the vertical displacements at the top of the column $\mathrm{C} 1$ for using different beam sections.

Fig. 25. The axial forces of the columns $\mathrm{C} 2$ against temperature for using different beam sections.

Fig. 26. The failure modes for the studied frame with different beam sections.

Fig. 27. Configuration of the frame restrained with axial elastic springs.

Fig. 28. Comparison of the vertical displacements at the top of the column $\mathrm{C} 1$ for using different lateral stiffness ratios.

Fig. 29. The axial forces of the columns C2 against temperature for using different lateral stiffness ratios.

Fig. 30. The failure process of the braced frame.

Fig. 31. The axial force in connection J1 with different lateral bracing system against temperature. 


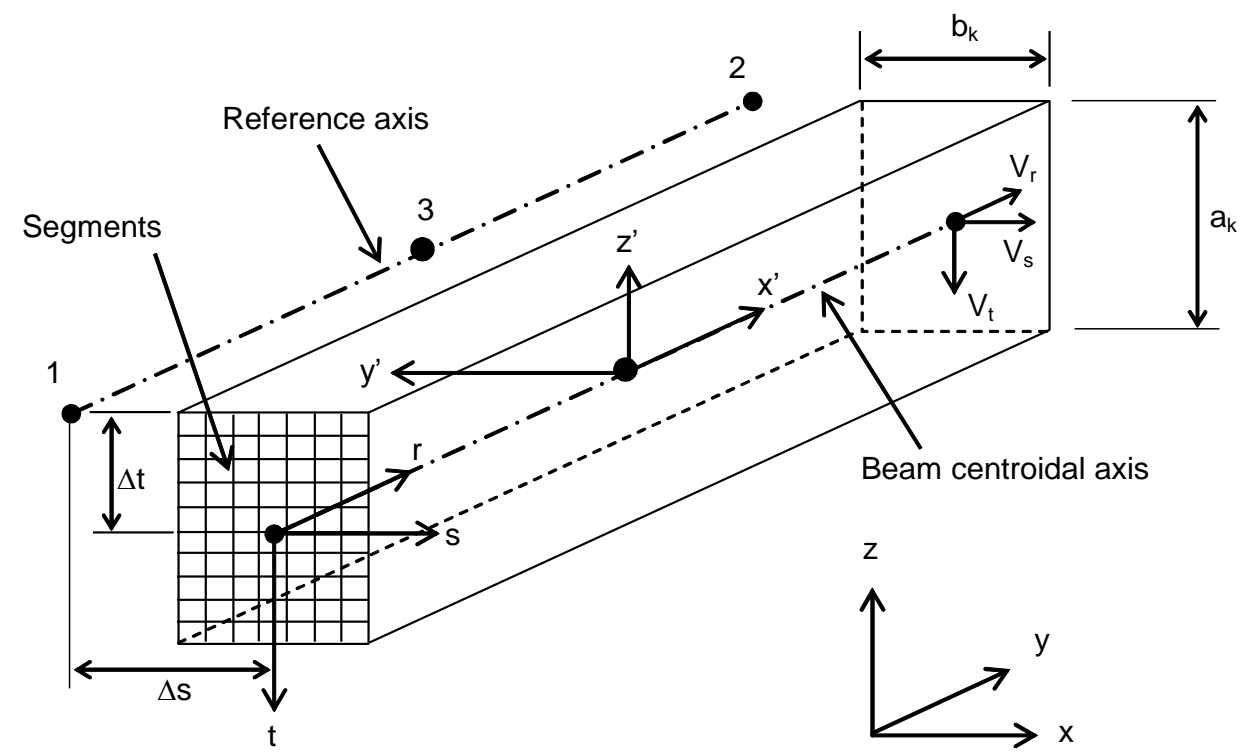

Fig.1 Three dimensional 3-noded beam-column element.

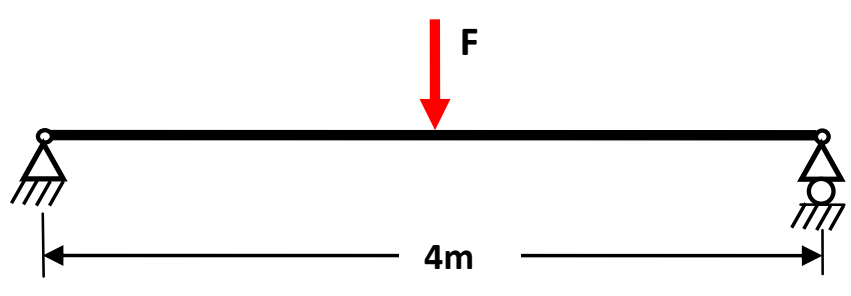

Dimension

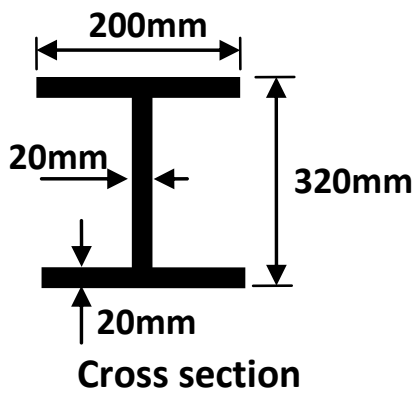

Fig.2 A simply supported beam for forced vibration test. 


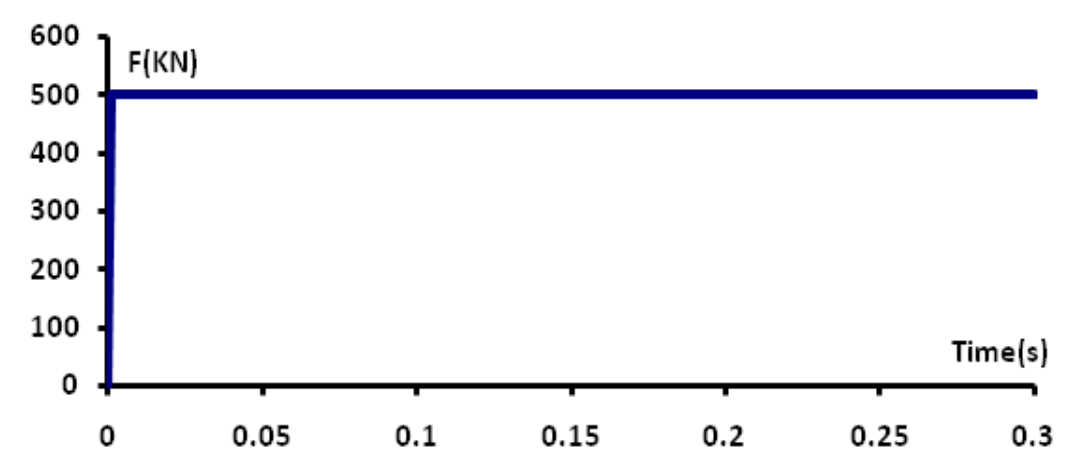

Fig.3 Load-time curve.

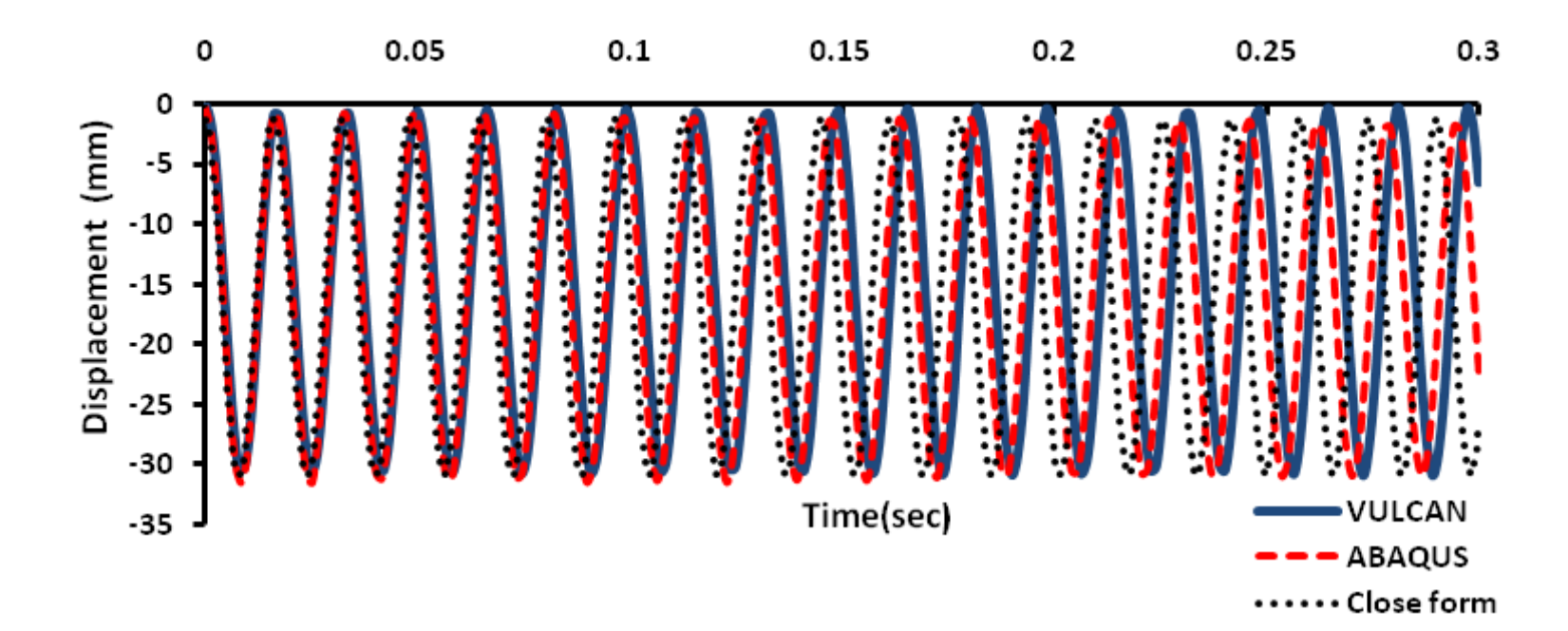

Fig. 4 Comparisons of predicted mid-span displacements against time for the three procedures. 


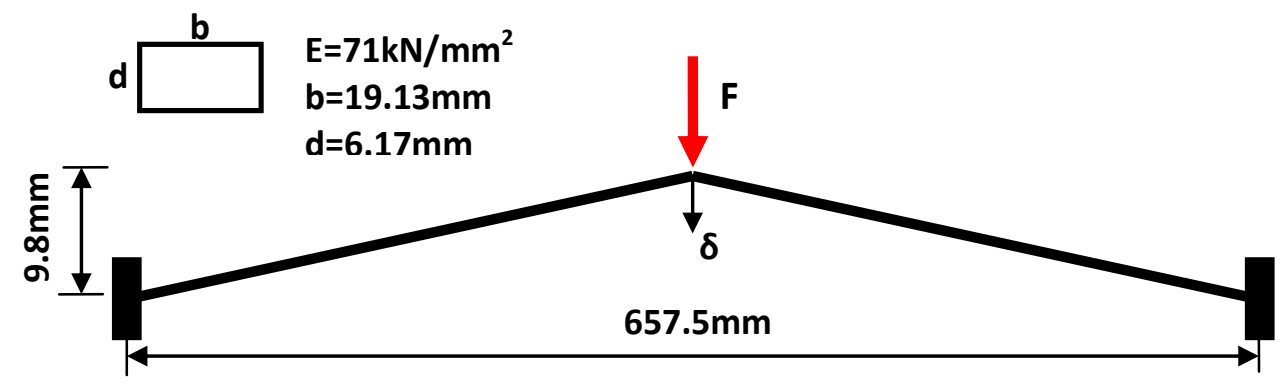

Fig. 5 Williams toggle frame [31].

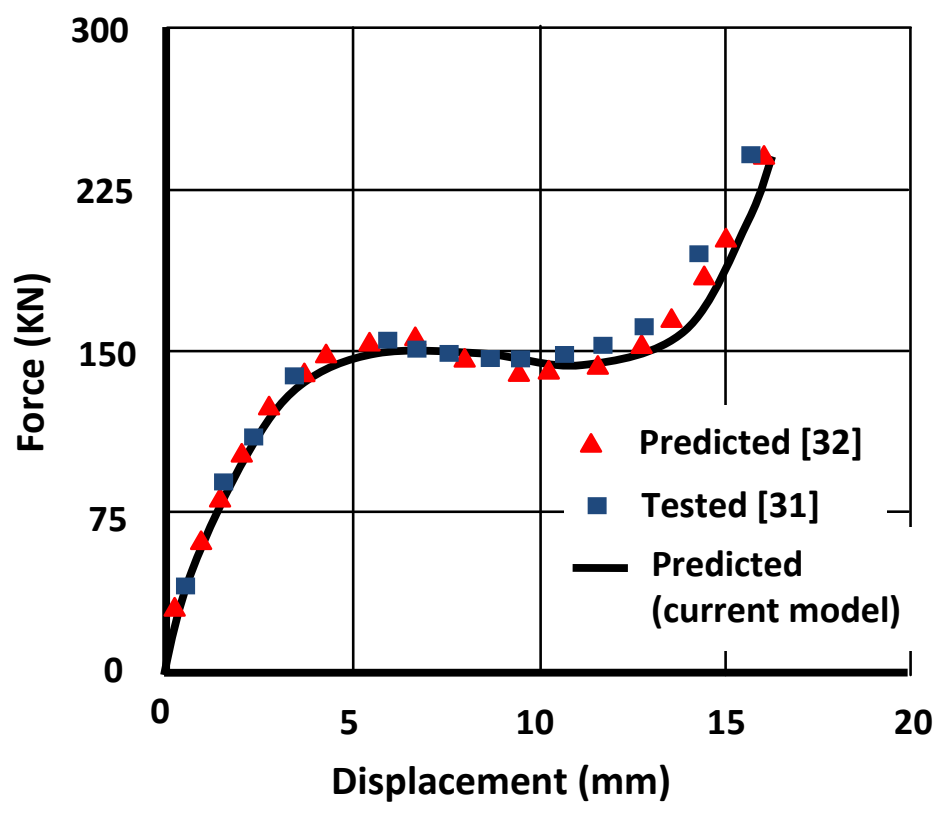

Fig. 6 Comparisons of predicted vertical displacement at apex with test results. 


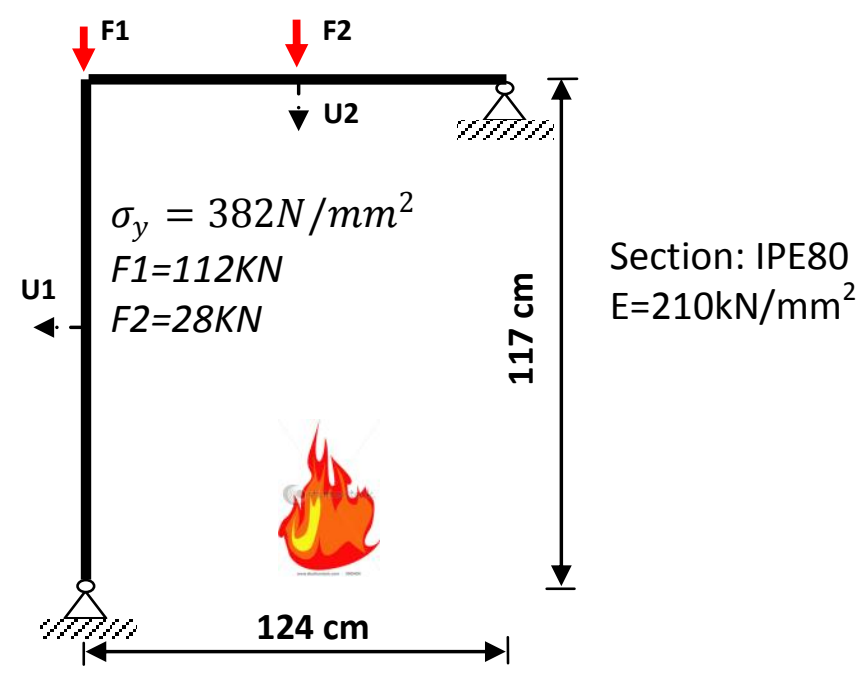

(a) EHR frame

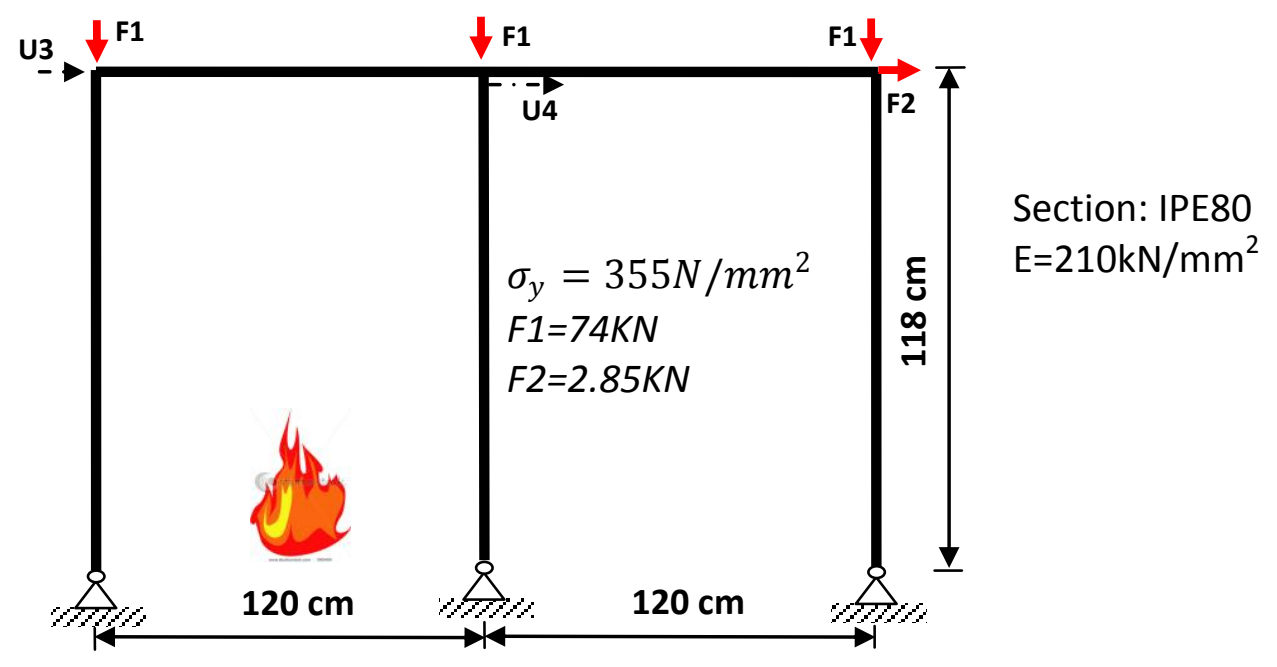

(b) ZSR frame

Fig. 7 Tested steel frames in fire [33]: (a) EHR frame; (b) ZSR frame. 


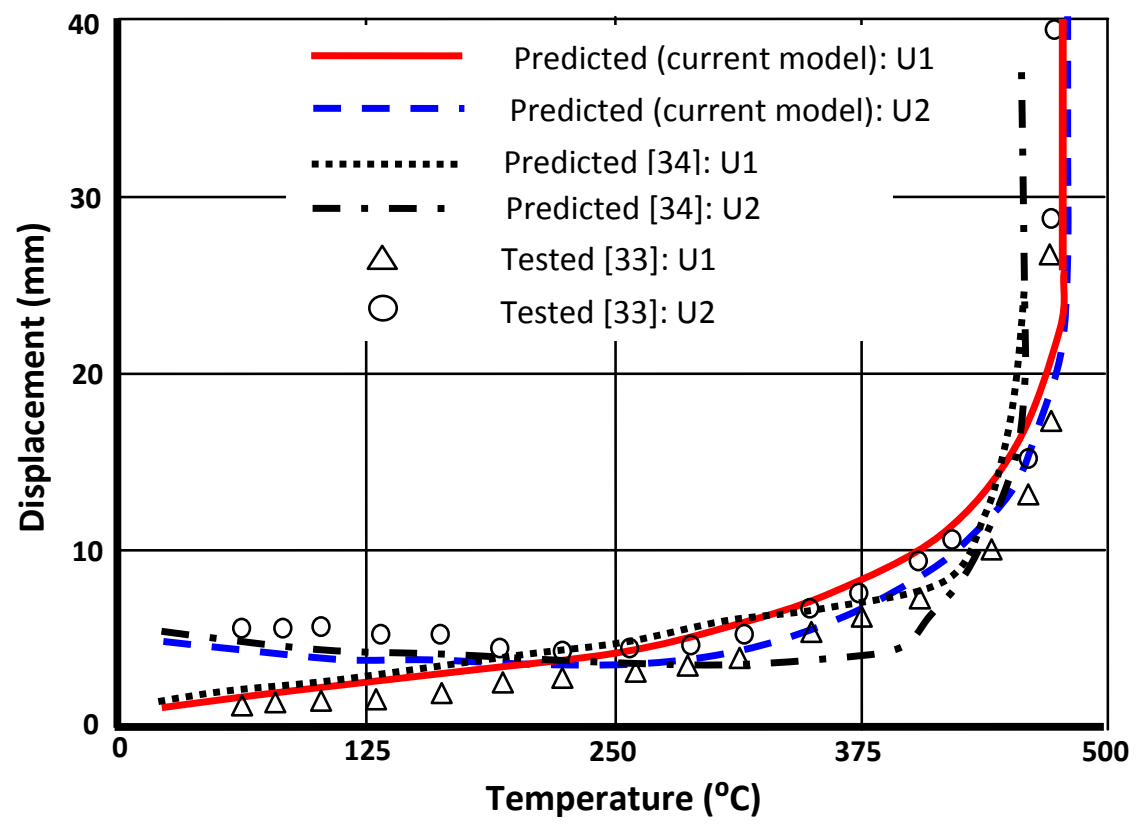

(a) EHR Frame

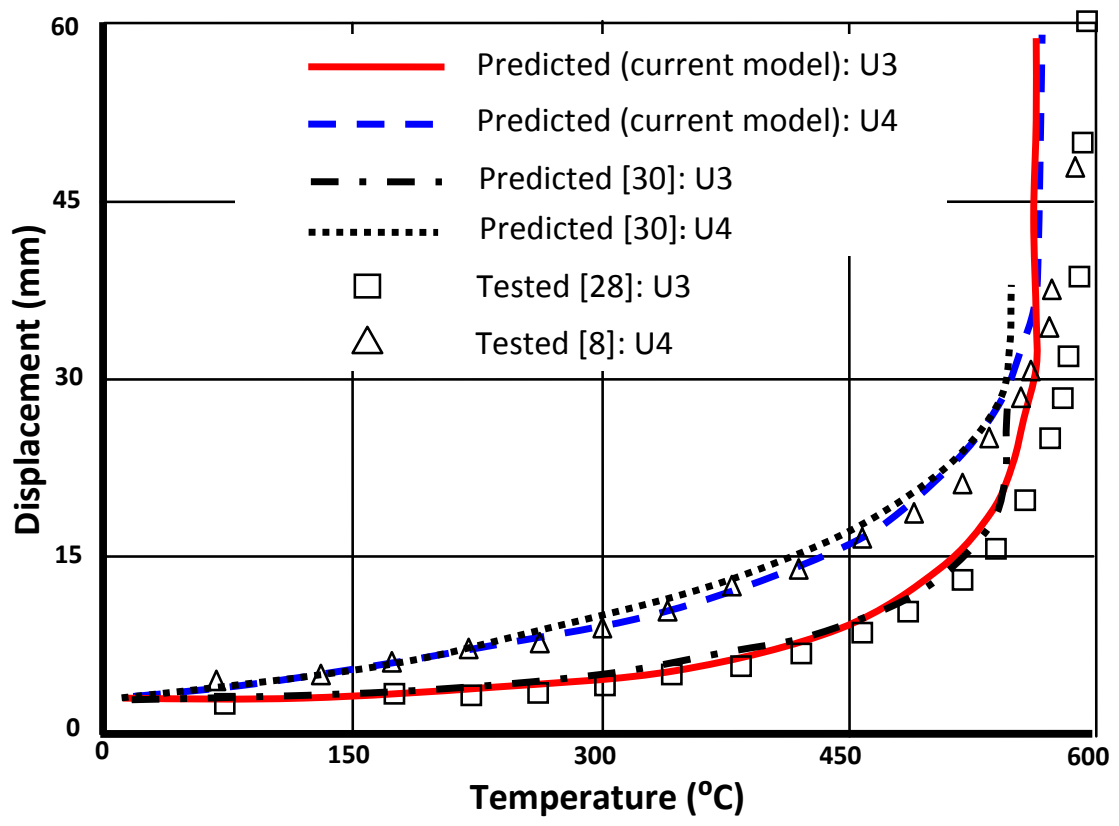

(b) ZSR Frame

Fig. 8 The comparisons of predicted and tested displacements at different locations within the frames. 


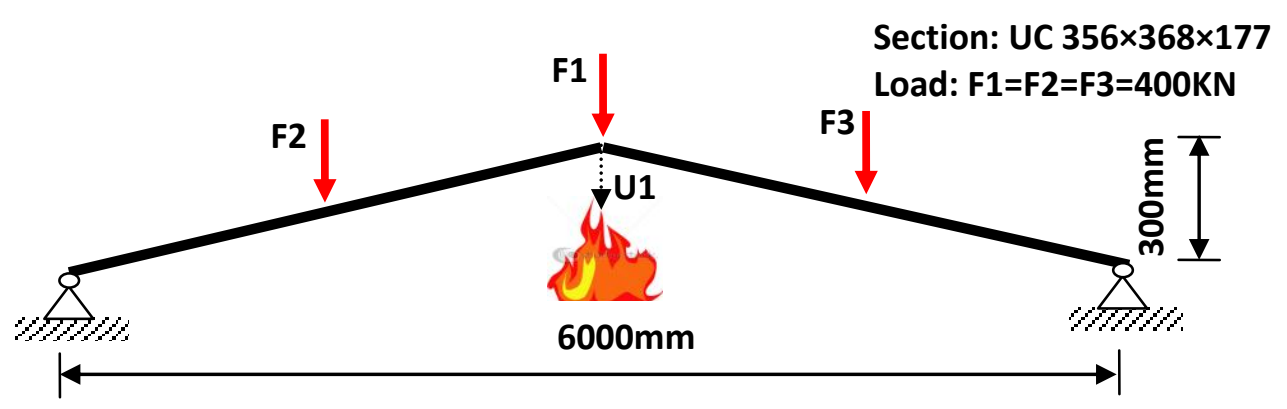

Fig. 9 The details of studied steel frame in fire.

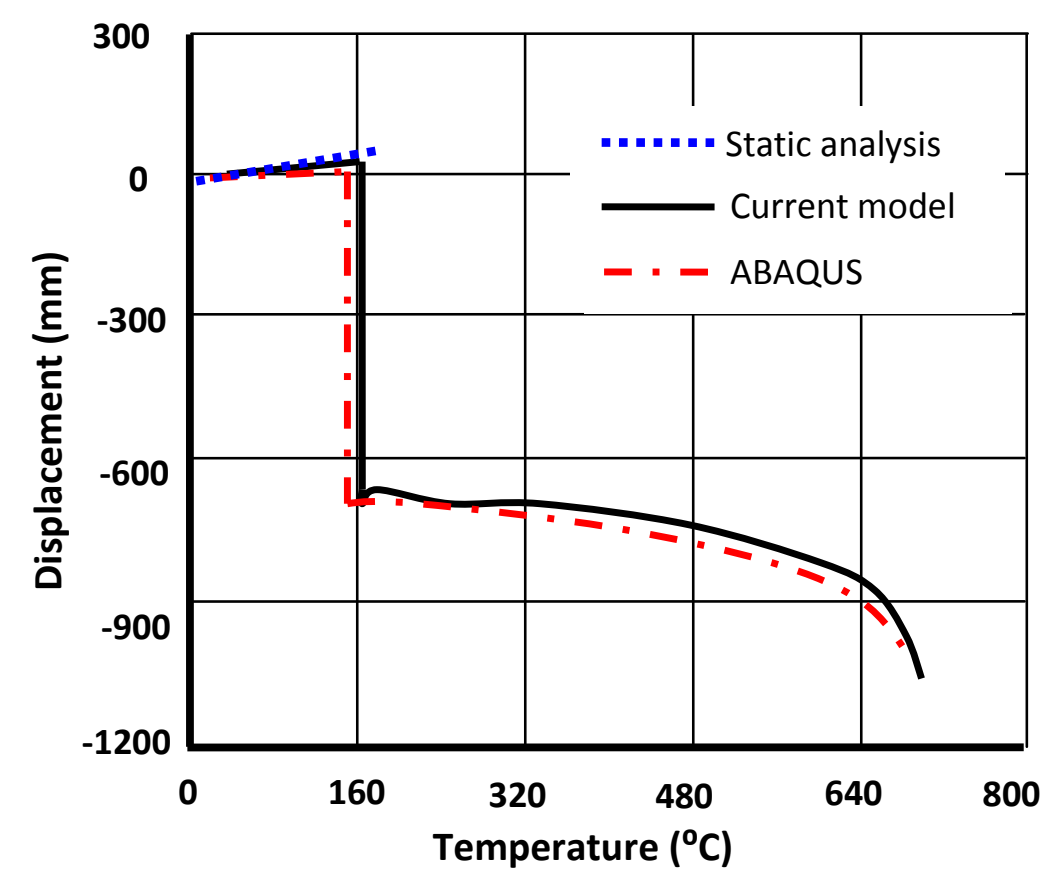

Fig. 10 Comparison of the predicted vertical displacement U1 by using different models. 


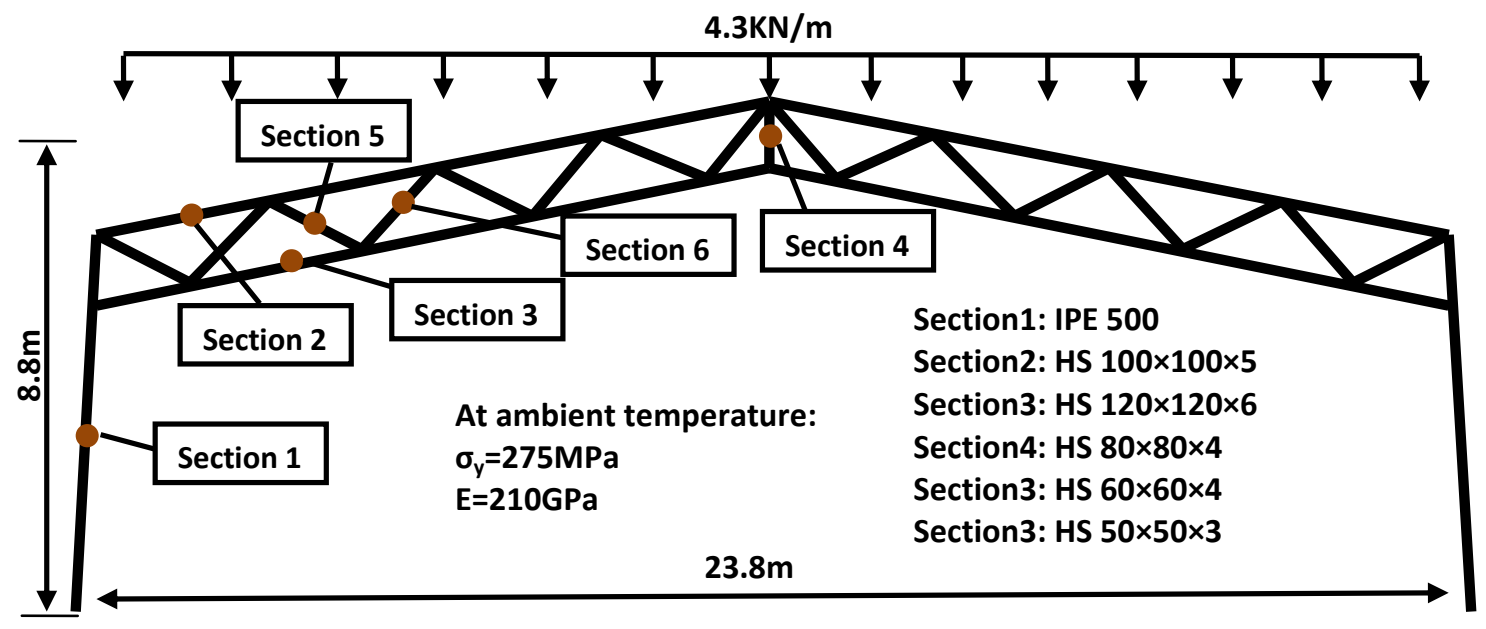

Fig.11 The details of the analysed truss frame in fire.

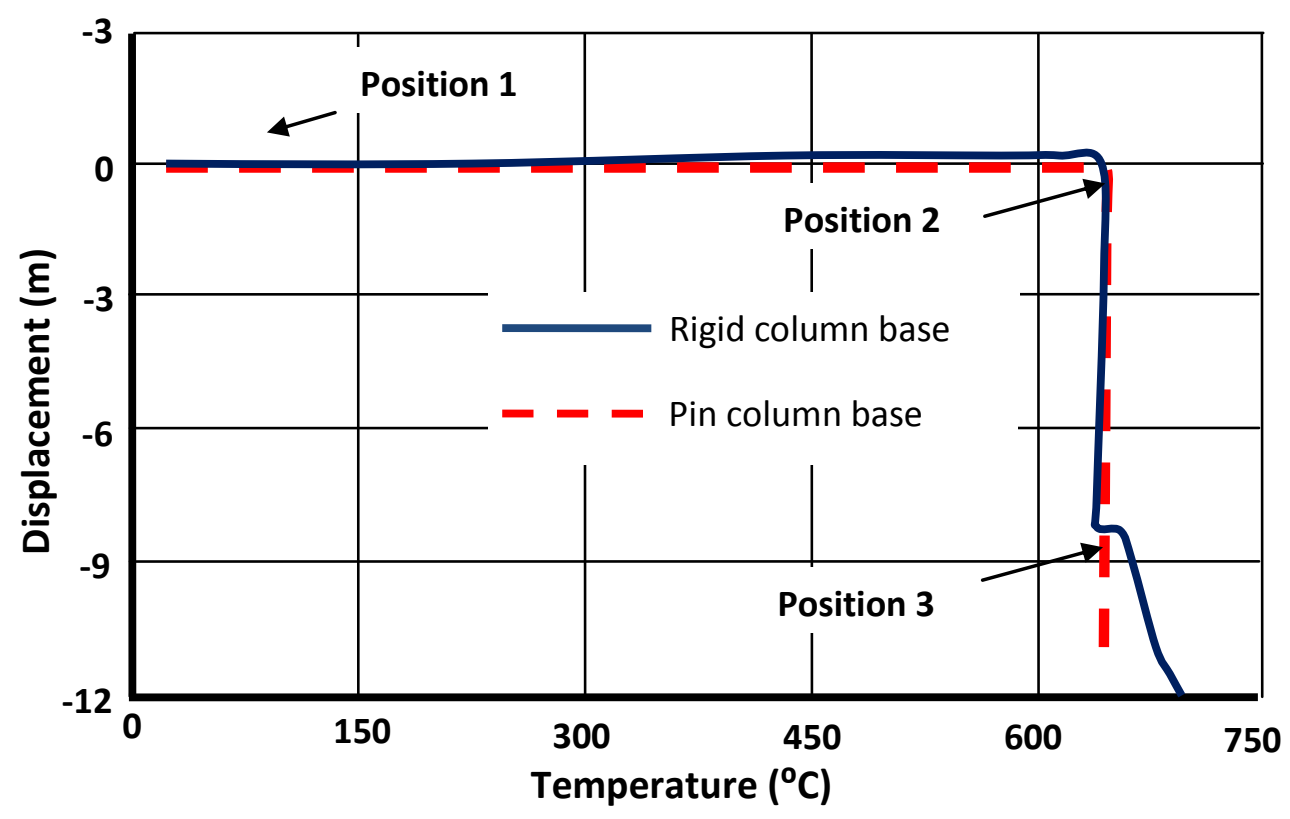

Fig.12 The vertical displacement at the apex of the frame against temperature. 

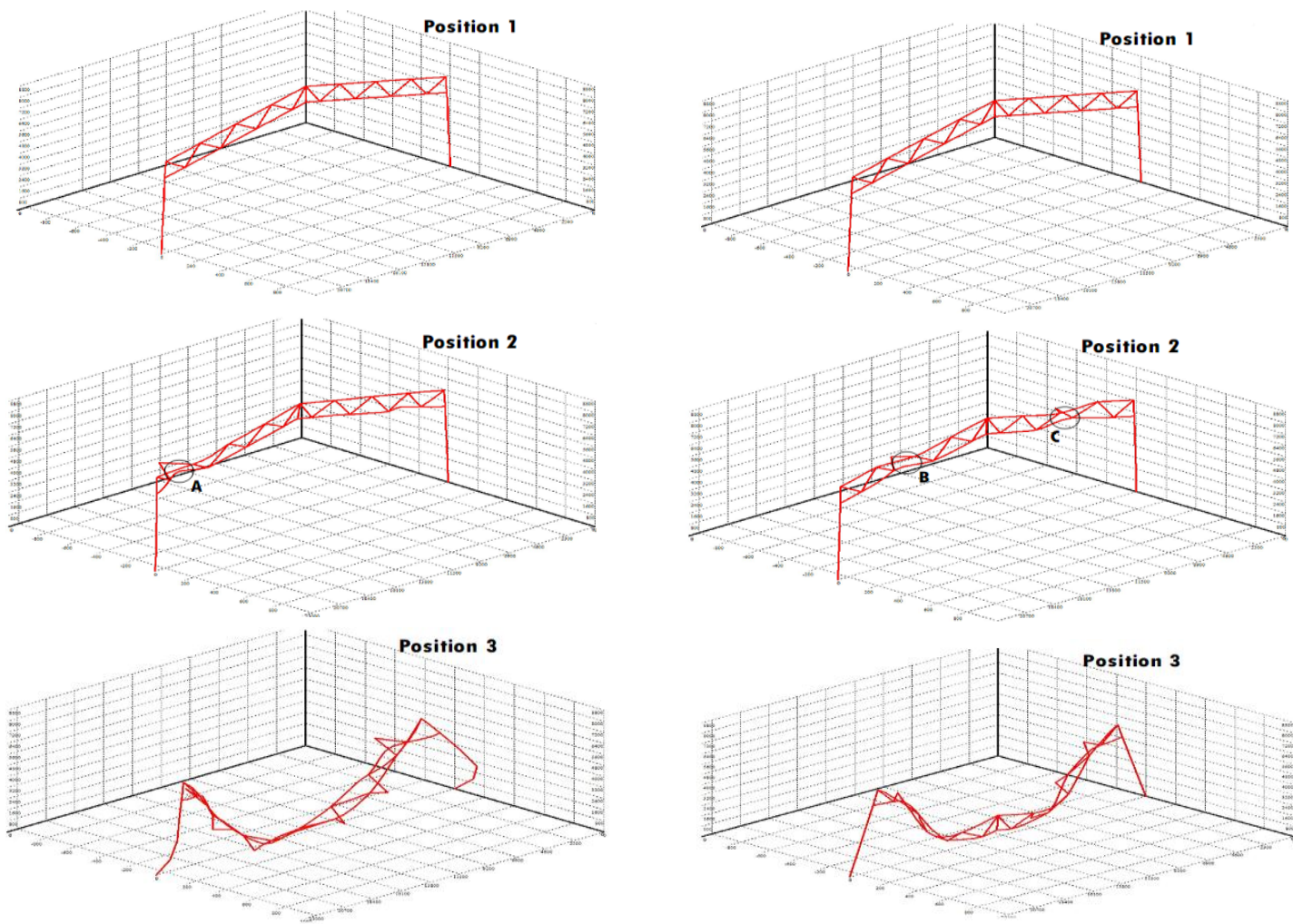

Rigid bases

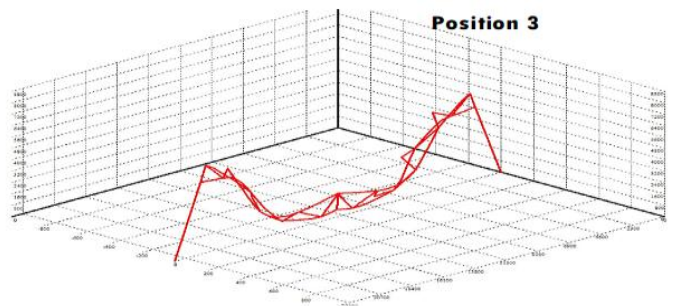

Pinned bases

Fig.13 The failure process of the truss frame for different column base conditions in fire.

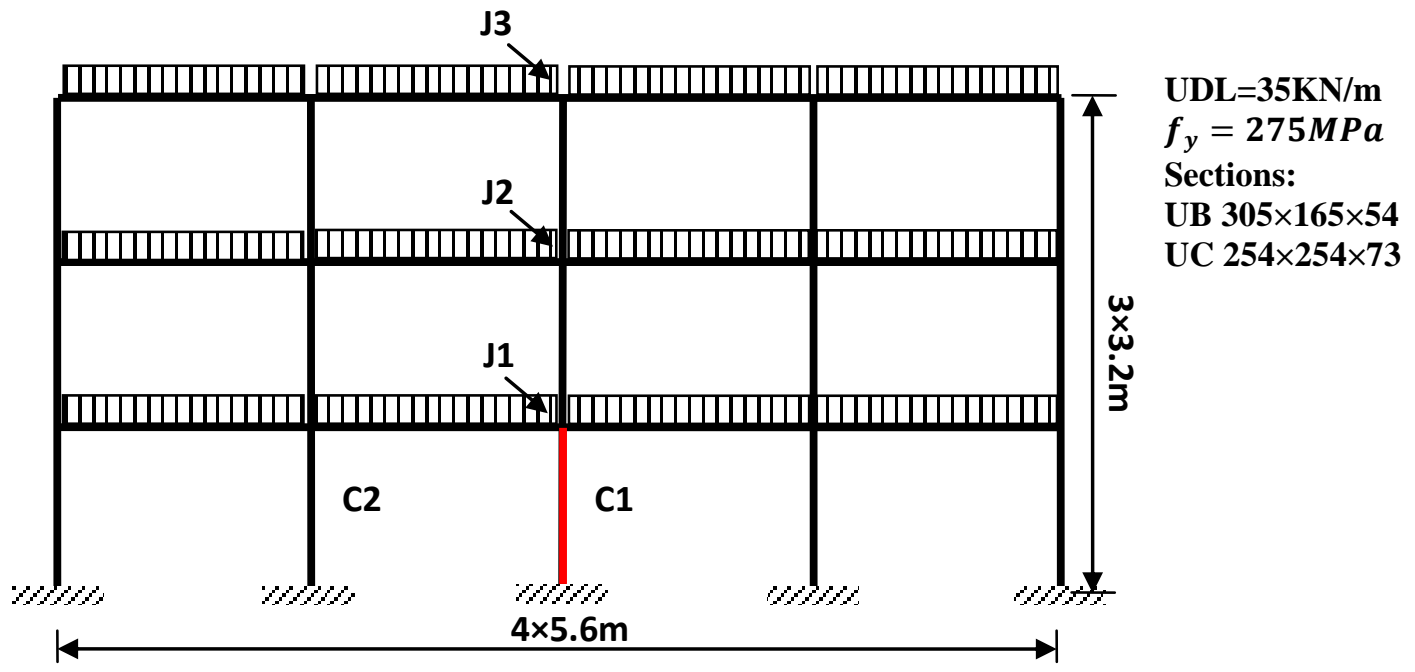

Fig.14 Details of 2D steel frame with one column heated. 


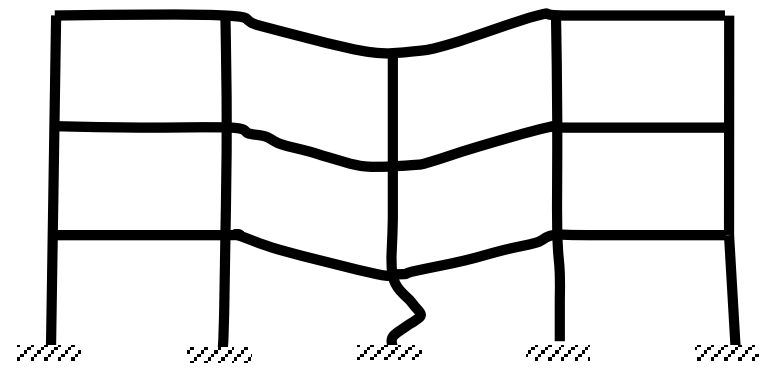

(a) Failure stage I

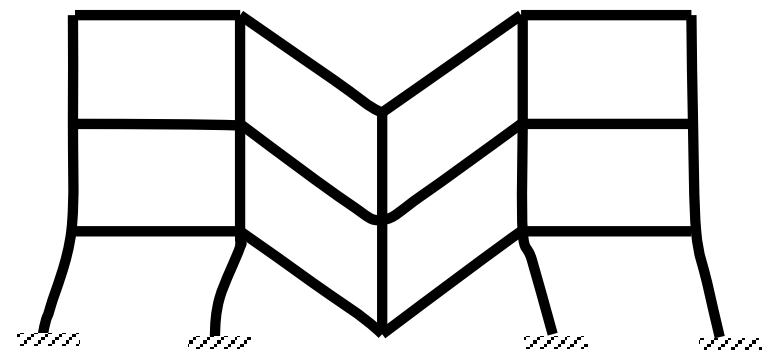

(b) Failure stage II

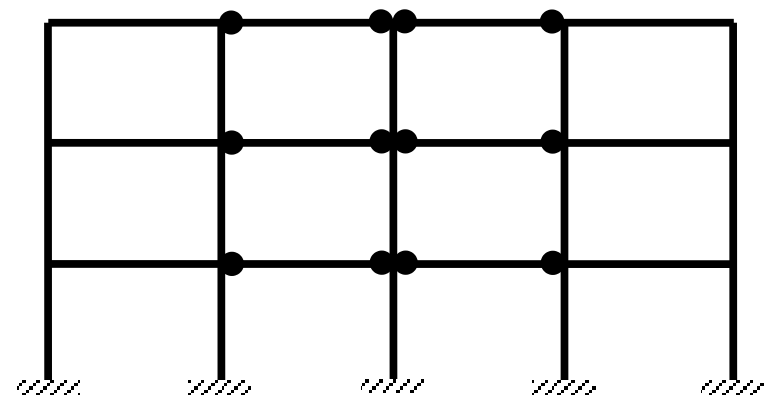

(c) Plastic hinges' development at failure stage I

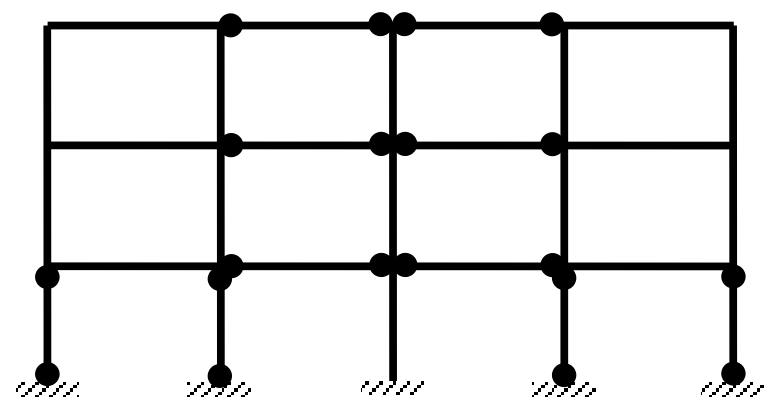

(d) Plastic hinges' development at failure stage II

Fig.15 The failure modes and the development of the plastic hinges for the studied frame. 


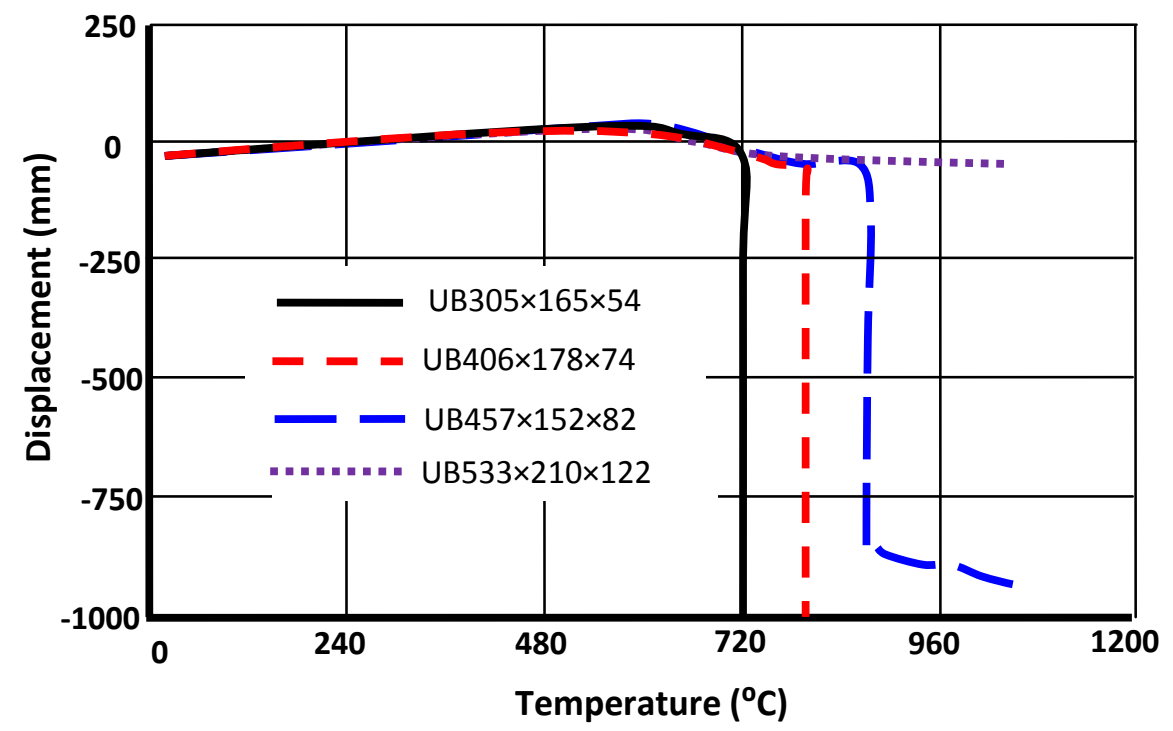

Fig.16 Comparison of the vertical displacements at the top of the column $\mathrm{C} 1$ for using different beam sizes.

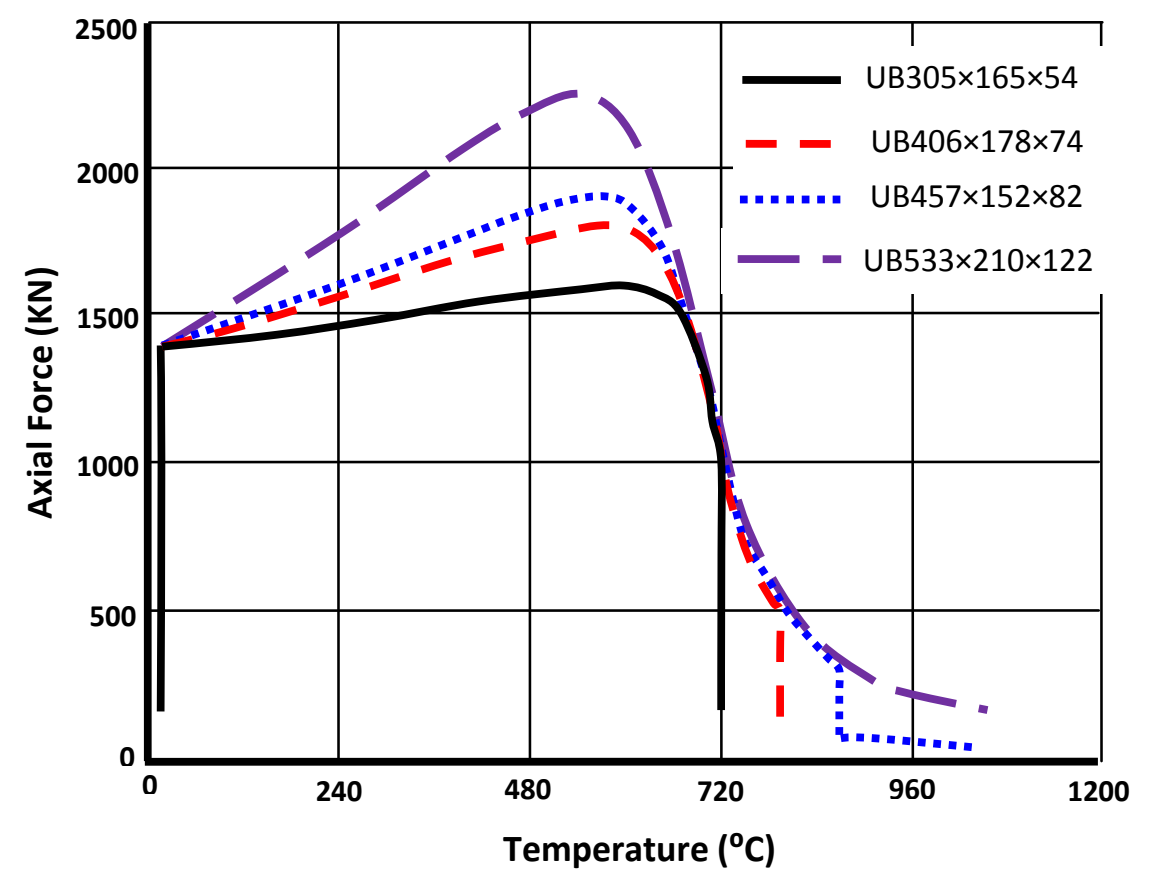

(a) Axial force in the column $\mathrm{C} 1$ 


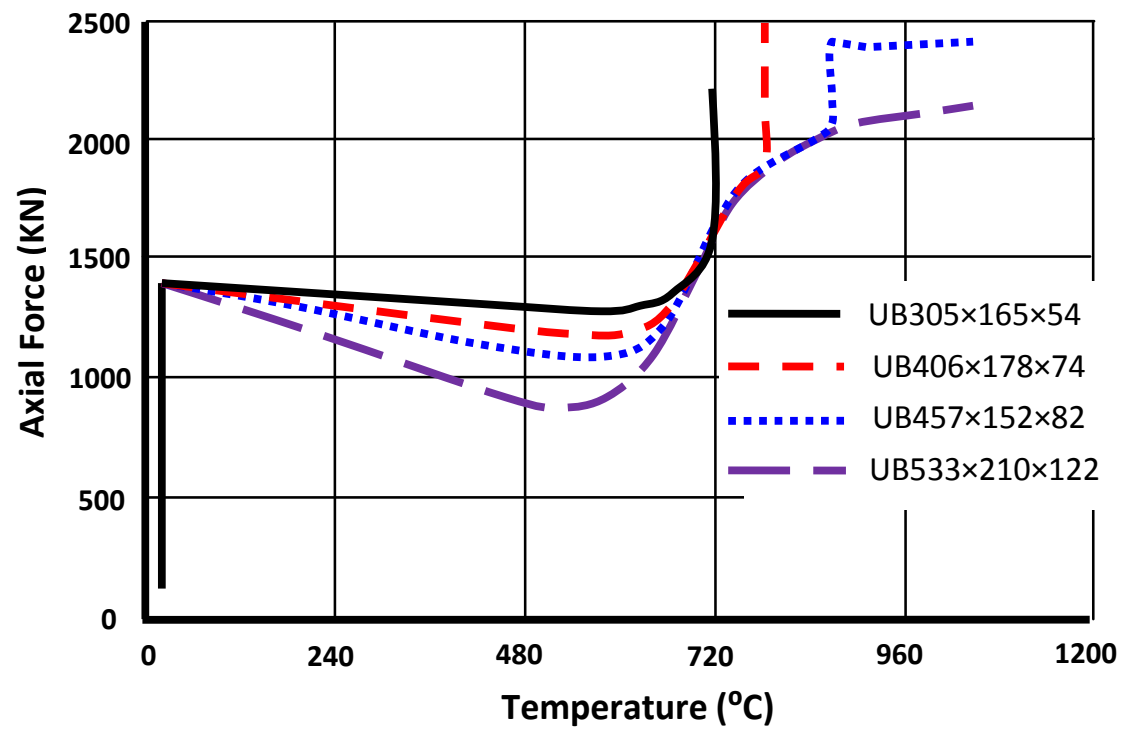

(b) Axial force in the column $\mathrm{C} 2$

Fig.17 The axial forces of the columns $\mathrm{C} 1$ and $\mathrm{C} 2$ against temperature for using different beam sizes.

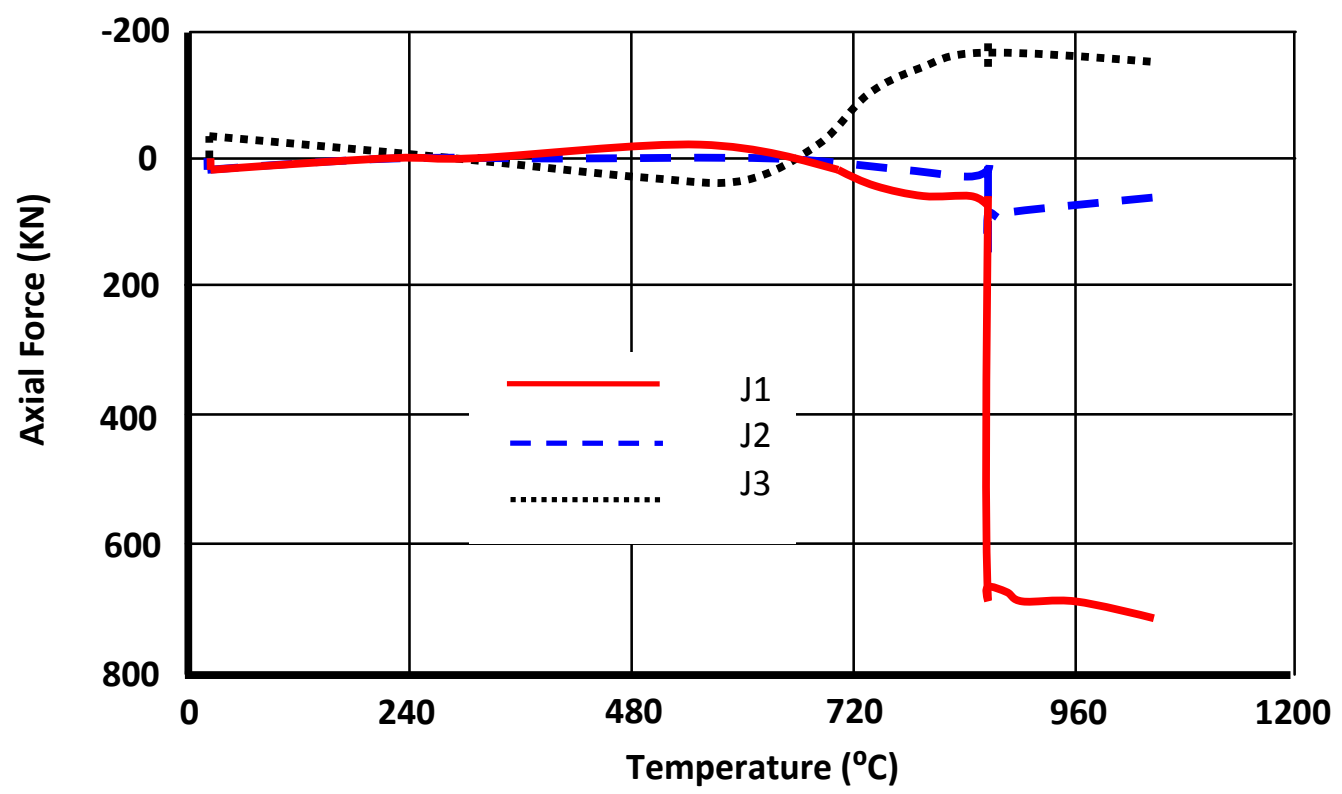

Fig.18 The axial forces in the connections J1, J2 and J3 against temperature. 


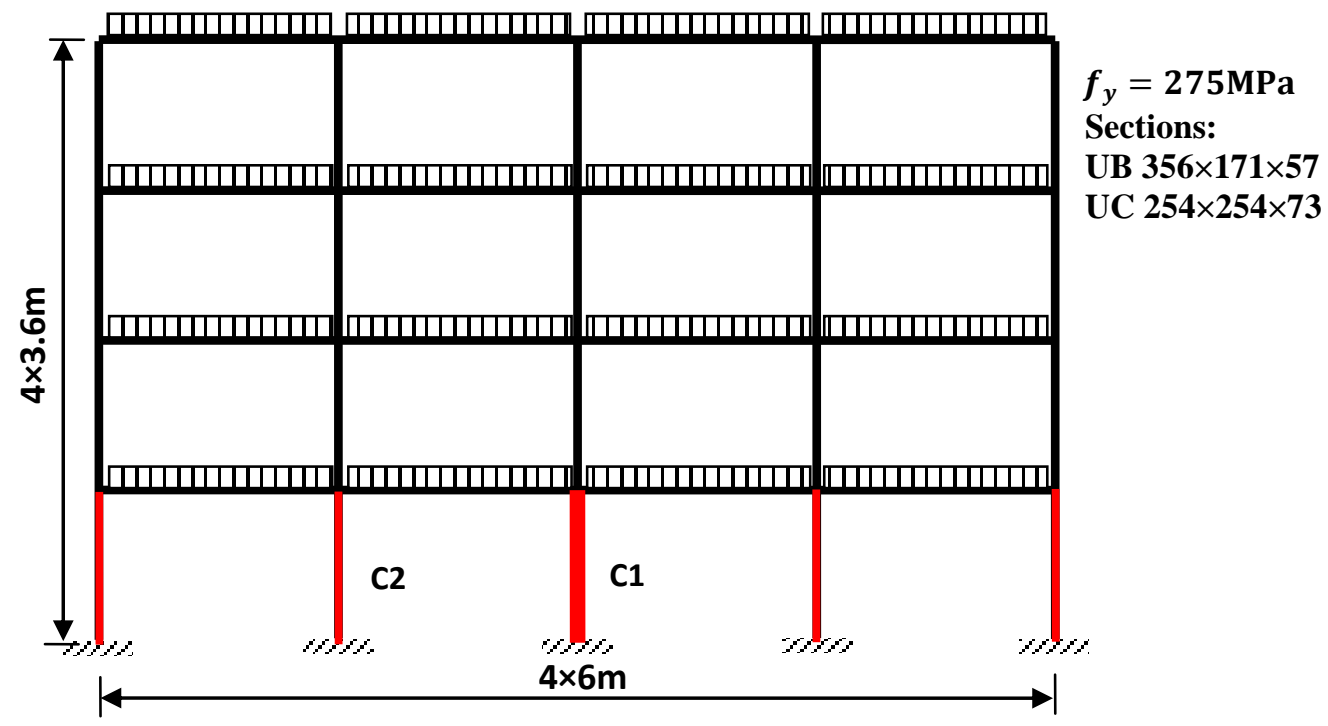

Fig.19 Details of 2D steel frame with several columns heated.

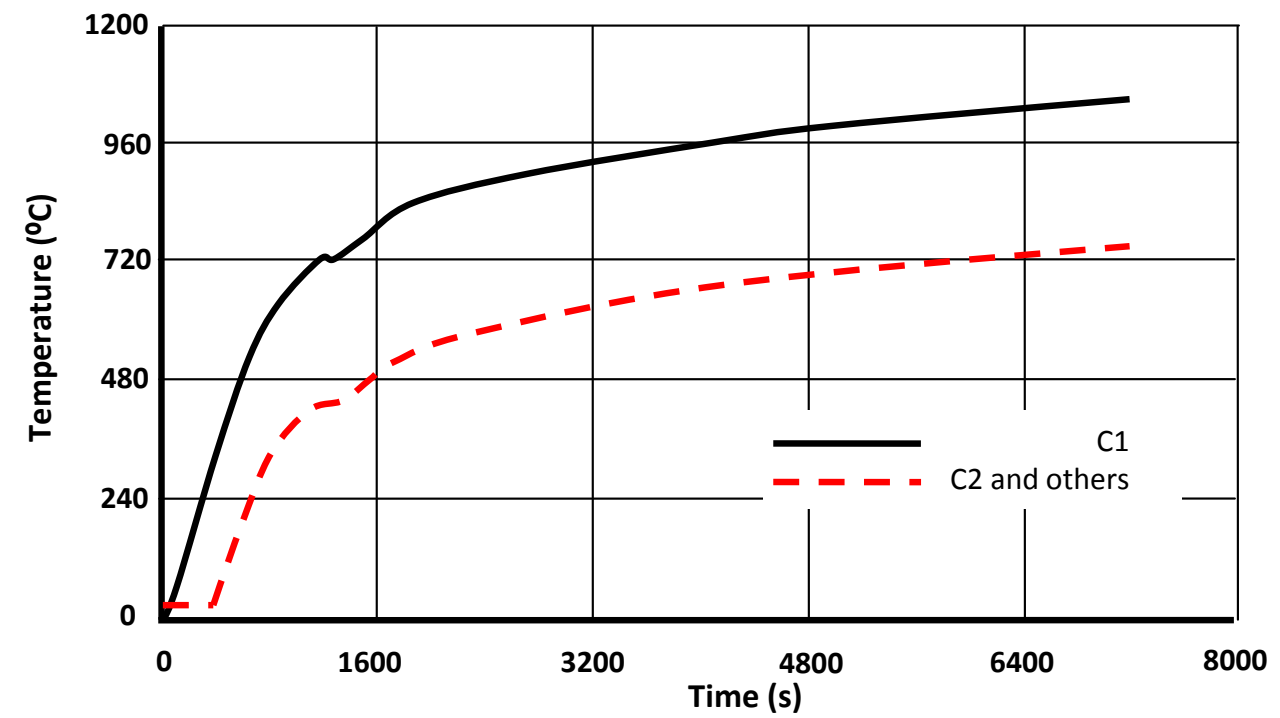

Fig.20 Temperatures against time for the heated columns. 


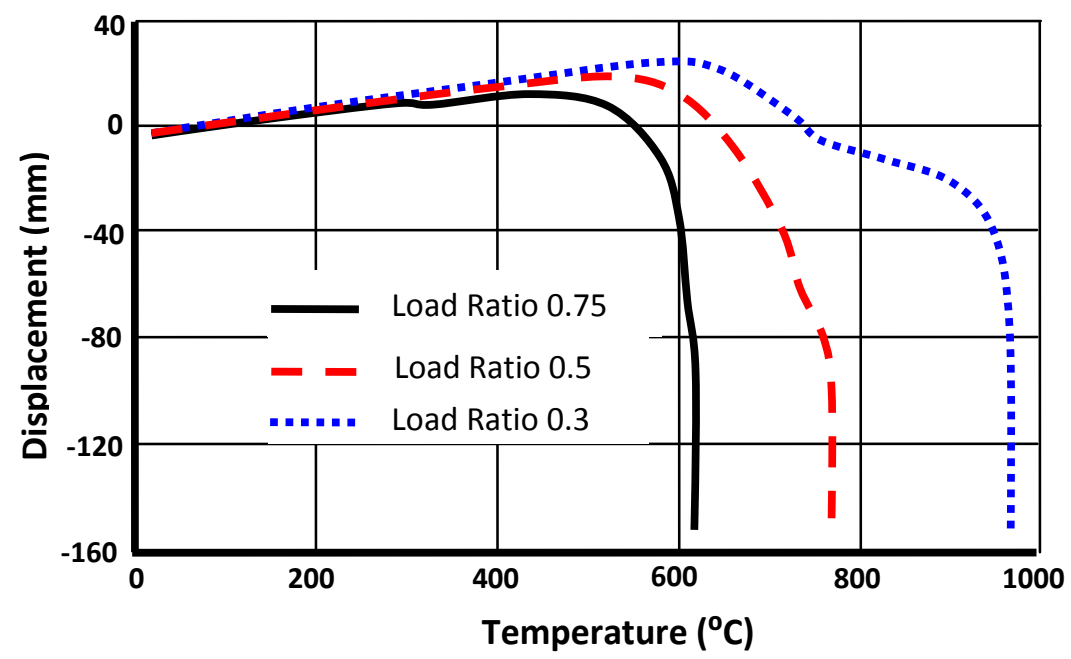

Fig.21 Comparison of the vertical displacements at the top of the column $\mathrm{C} 1$ for using different loadings.

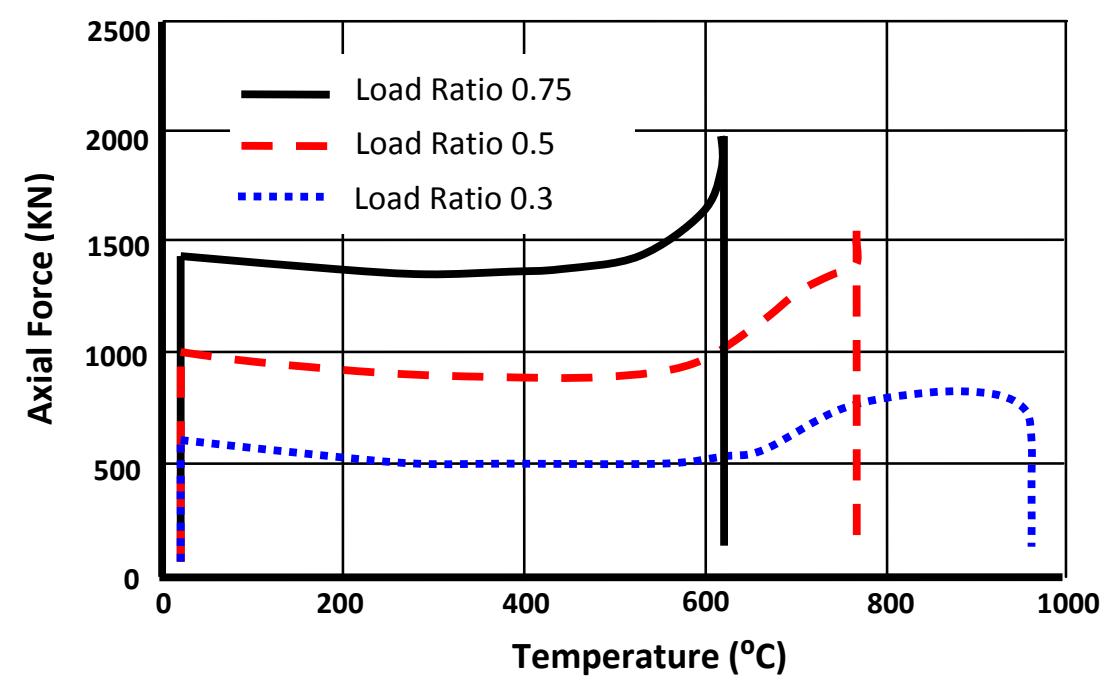

Fig.22 The axial forces of the columns $\mathrm{C} 2$ against temperature for using different loadings. 


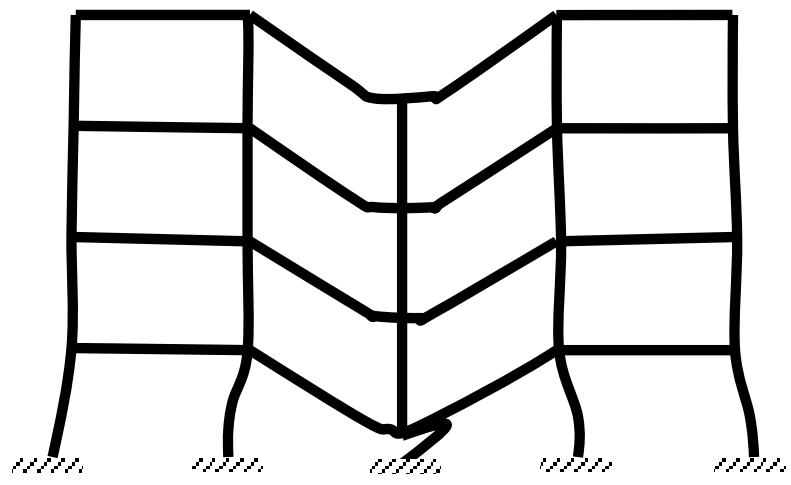

(a) Failure mode I

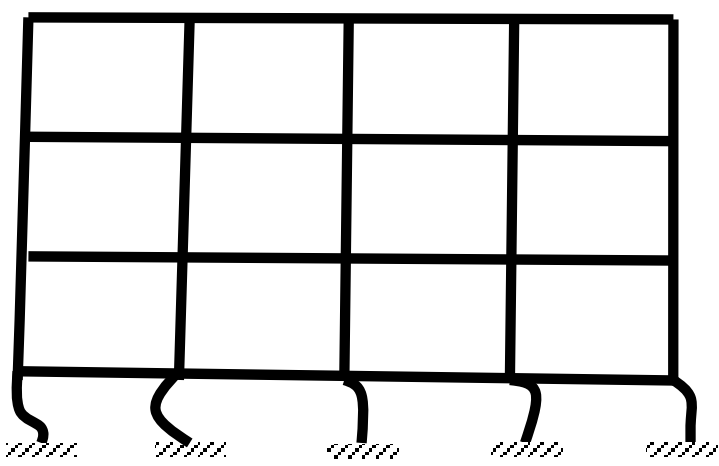

(b) Failure mode II

Fig.23 The failure modes for the studied frame with different loadings: (a) Failure mode I (loading ratio $=0.75$ and 0.5 ); (b) Failure mode II (loading ration $=0.3$ ). 


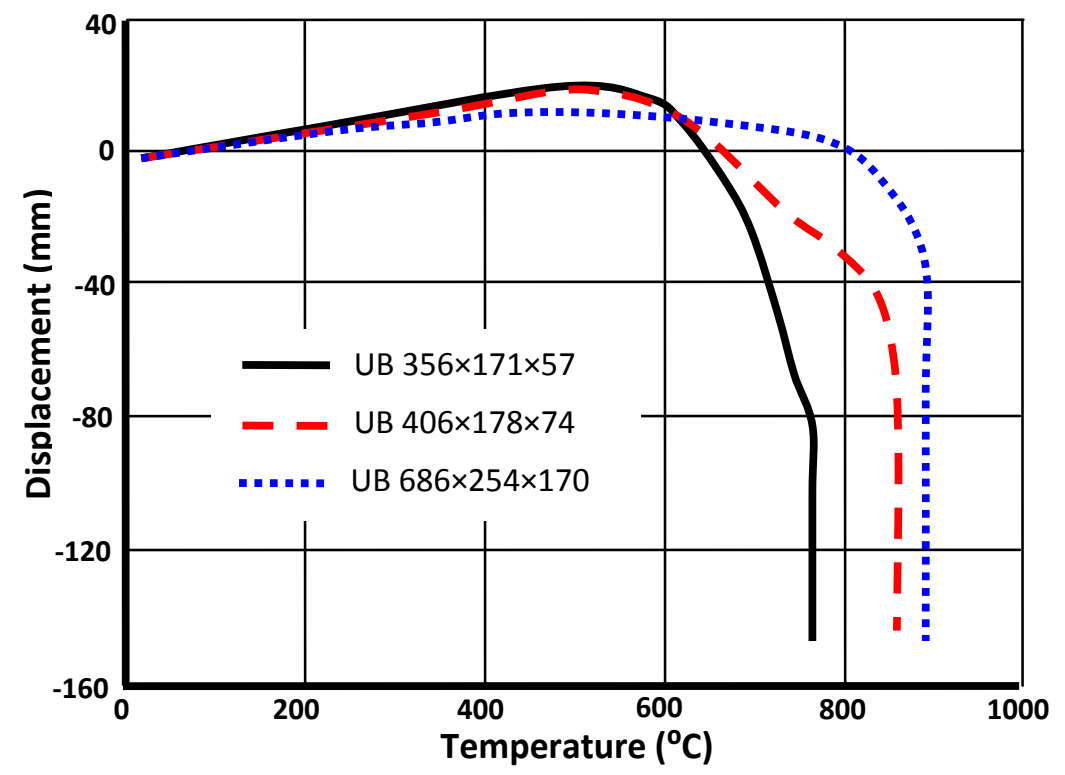

Fig.24 Comparison of the vertical displacements at the top of the column $\mathrm{C} 1$ for using different beam sections.

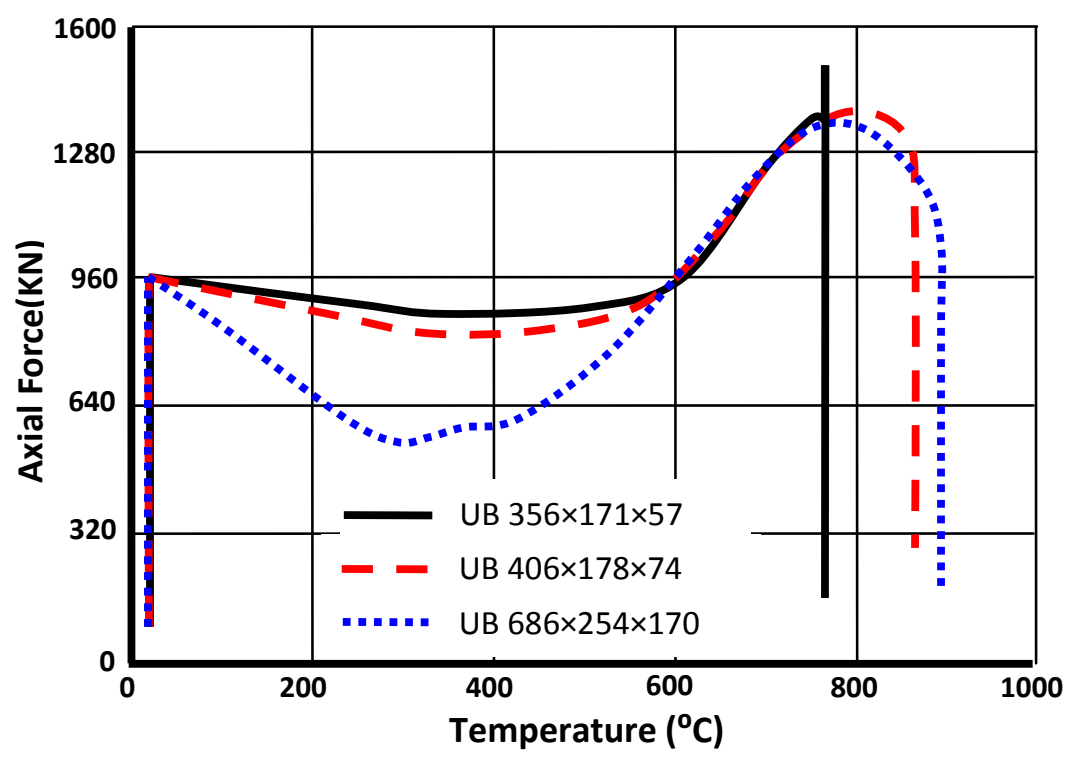

Fig.25 The axial forces of the columns C2 against temperature for using different beam sections. 


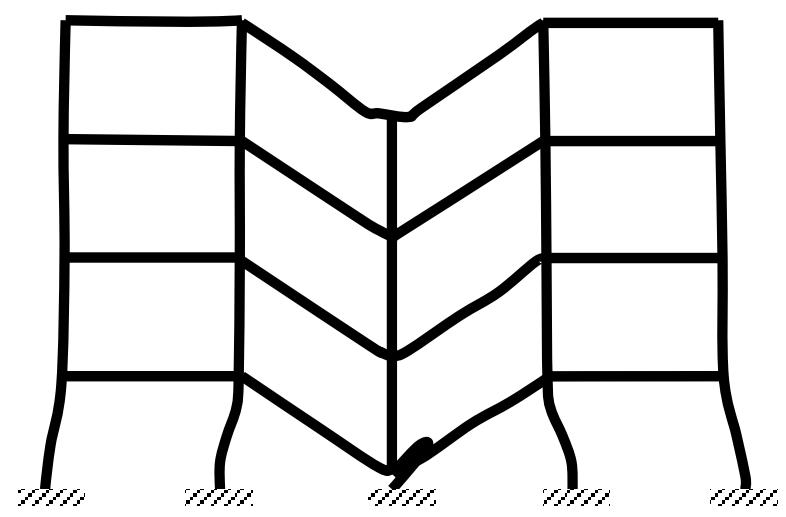

(a) Failure mode for the case with UB1

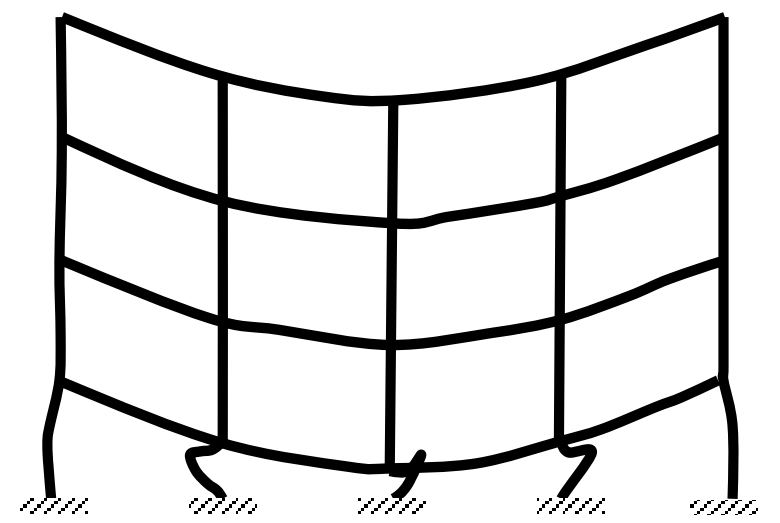

(b) Failure mode for the case with UB2

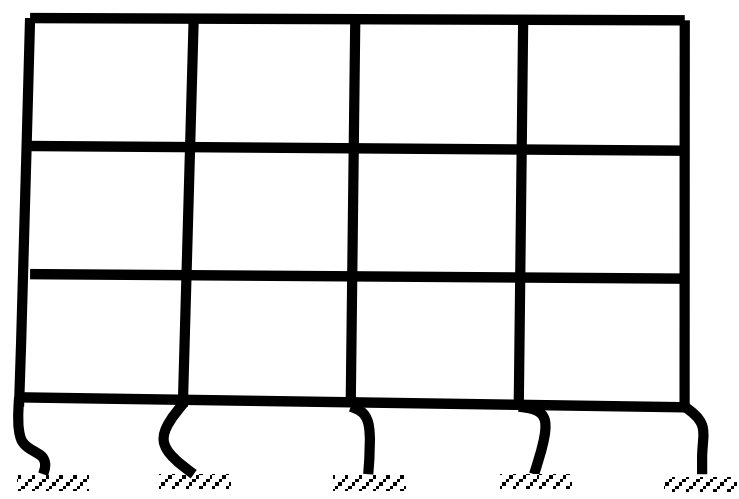

(c) Failure mode for the case with UB3

Fig.26 The failure modes for the studied frame with different beam sections. 


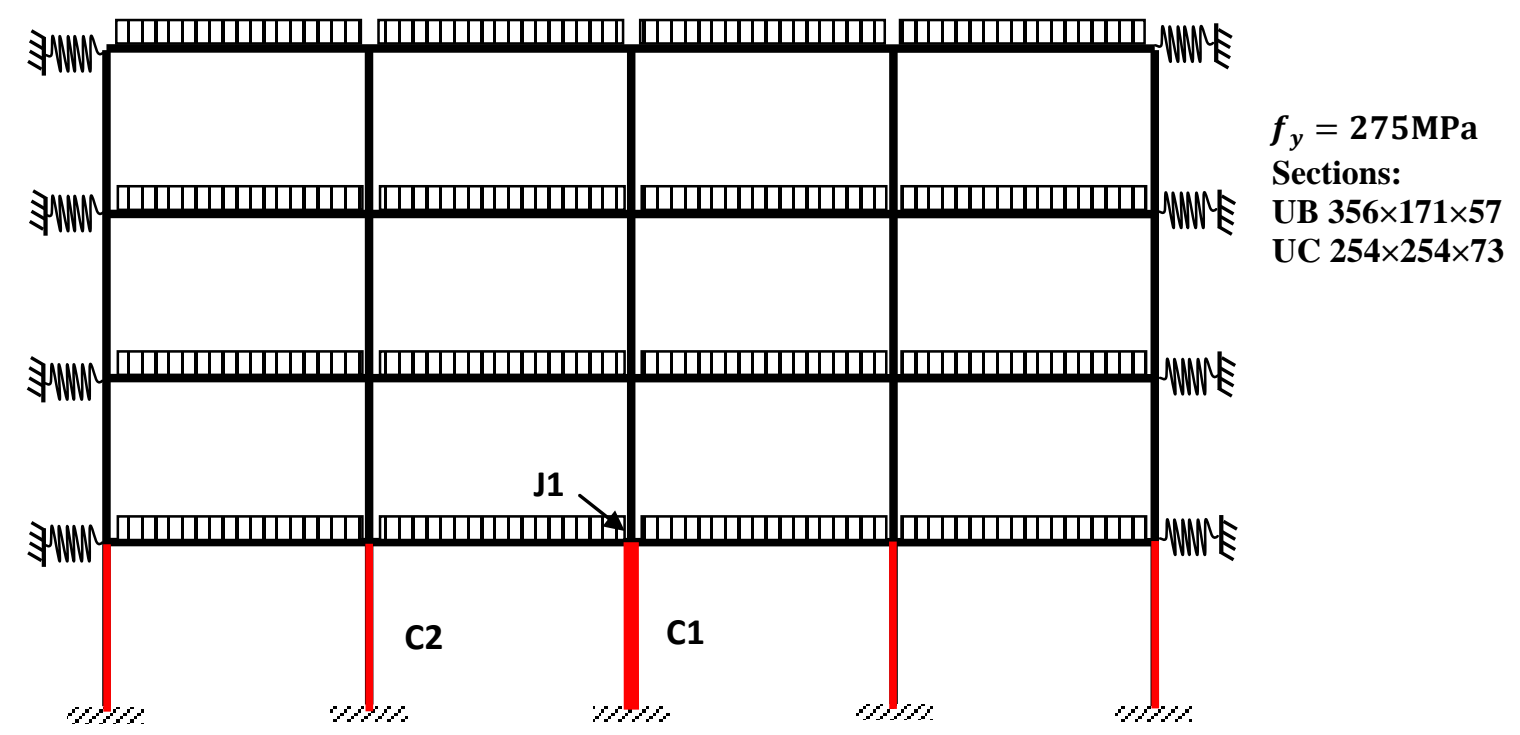

Fig.27 Configuration of the frame restrained with axial elastic springs.

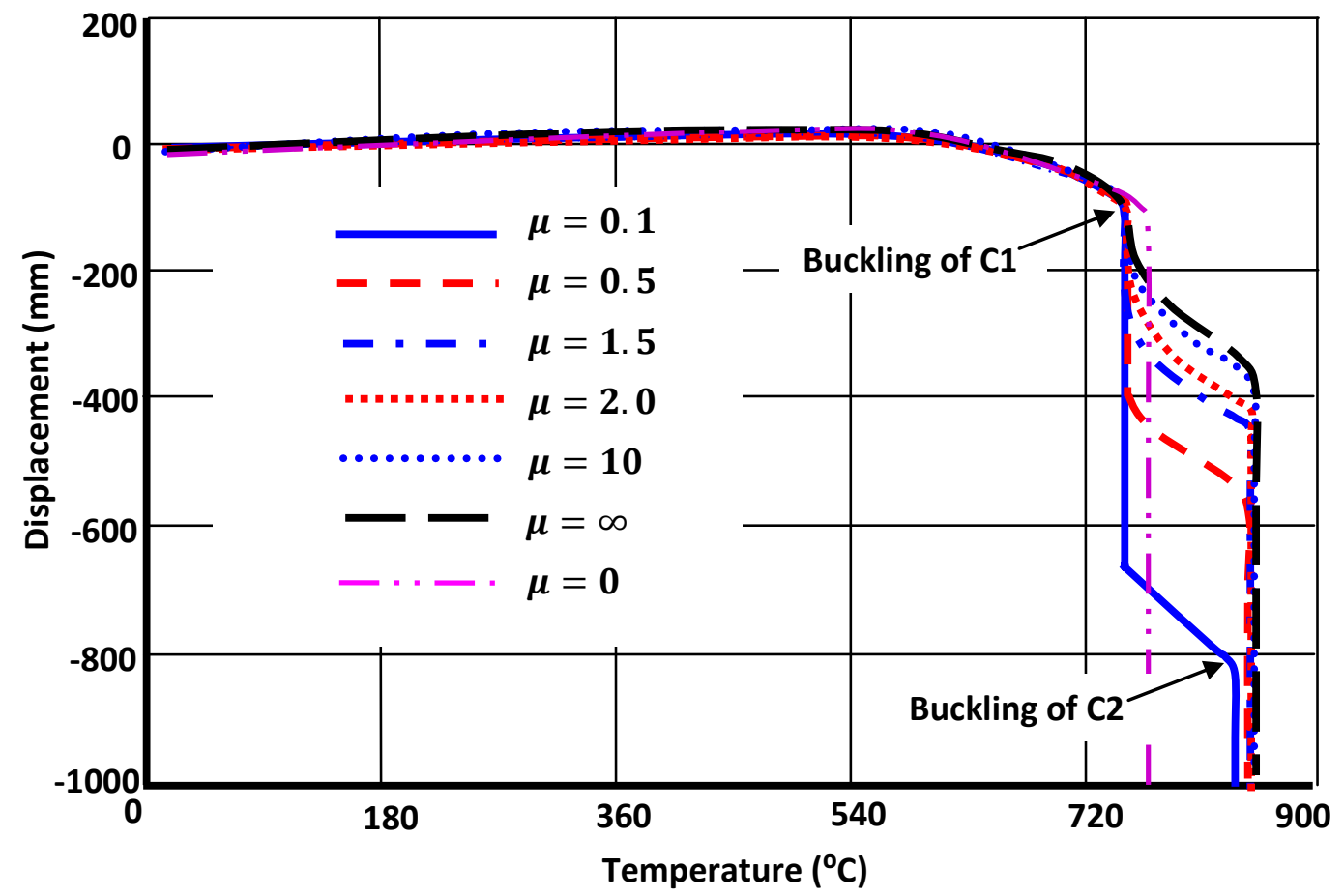

Fig.28 Comparison of the vertical displacements at the top of the column $\mathrm{C} 1$ for using different lateral stiffness ratios. 


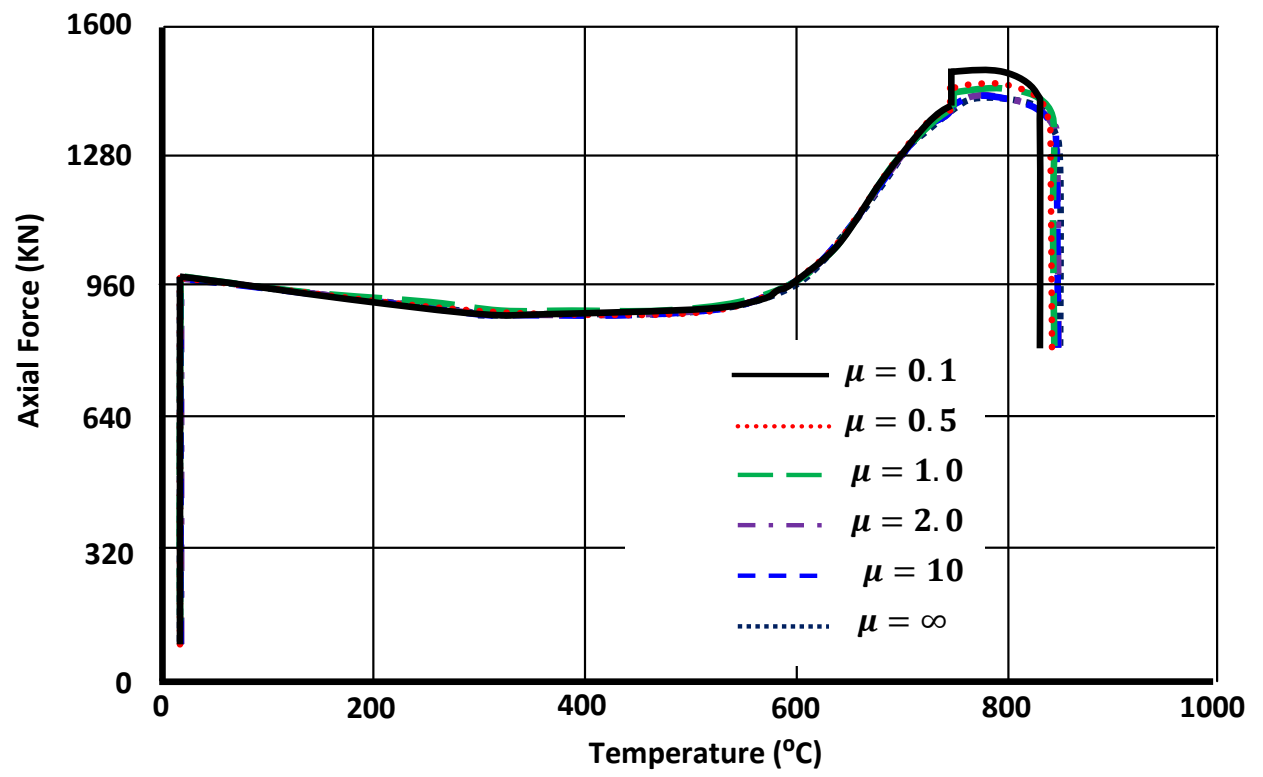

Fig.29 The axial forces of the columns C2 against temperature for using different lateral stiffness ratios.

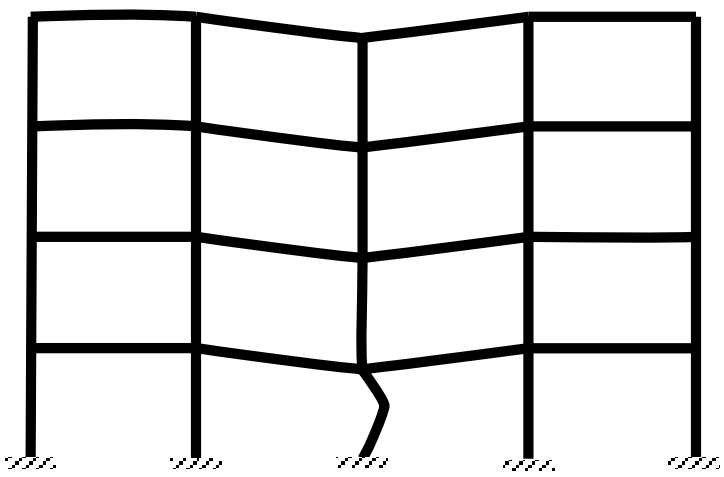

(a) Buckling of the column $\mathrm{C} 1$

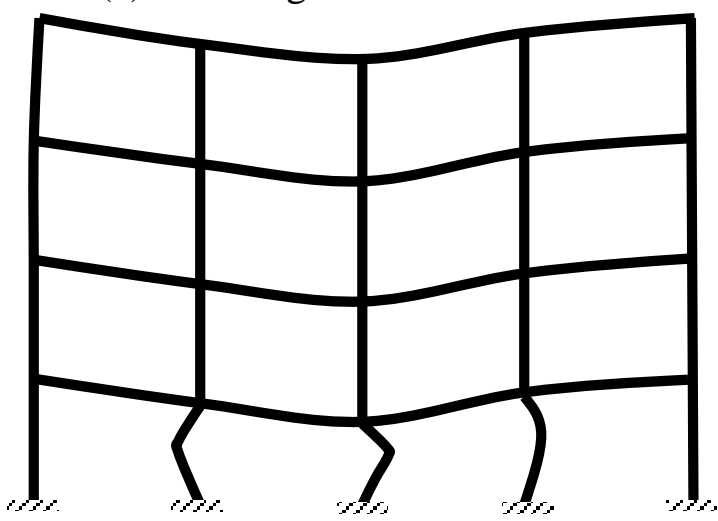


(b) Buckling of the column C2

Fig.30 The failure process of the braced frame.

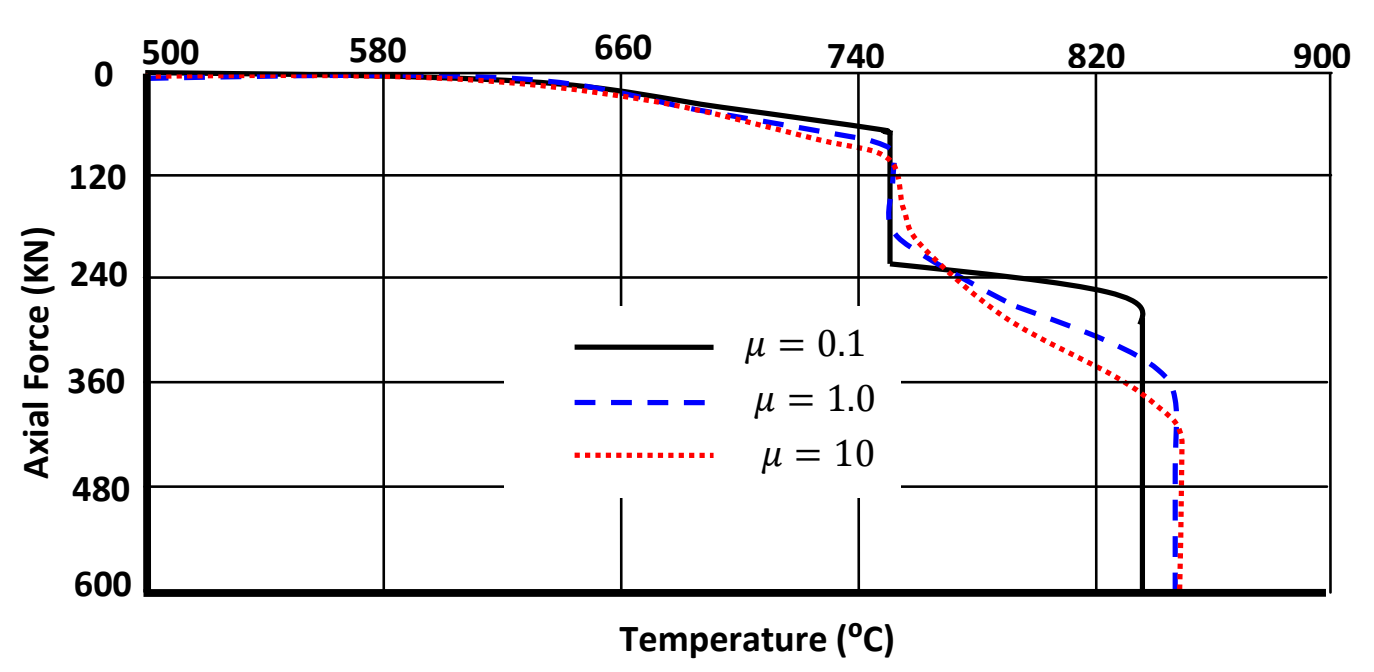

Fig.31 The axial force in connection $\mathrm{J} 1$ with different lateral bracing system against temperature. 
Table 1 Flowchart for explicit time integration.

1. Initial conditions and initialization:

Set initial value of material state variables and $\boldsymbol{u}_{0}^{n}, \dot{\boldsymbol{u}}_{0}^{n}$, compute mass matrix $M$ and initially estimate the time step.

2. Initialise the nodal internal force.

3. Compute the accelerations $\ddot{\boldsymbol{u}}_{i}^{n}=\left(\boldsymbol{M}^{n}\right)^{-1}\left(\boldsymbol{Q}_{i}^{n}-\boldsymbol{F}_{i}^{n}-\boldsymbol{D}_{i}^{n}\right)$

4. Time update: $t_{i+1}^{\text {i }}=t_{i}^{\text {i }}+\Delta t_{i} ; \Delta t_{i+1 / 2}^{\text {; }}=\left(\Delta t_{i}^{\text {i }}+\Delta t_{i+1}^{\text {; }}\right) / 2$

5. First partial update nodal velocities: $\dot{\boldsymbol{u}}_{i+1 / 2}^{n}=\dot{\boldsymbol{u}}_{i-1 / 2}^{n}+\Delta t_{i}: \ddot{\boldsymbol{u}}_{i}^{n}$

6. Enforce boundary conditions.

7. Update the nodal displacements: $\boldsymbol{u}_{i+1}^{n}=\boldsymbol{u}_{i}^{n}+\Delta t_{i+1 / 2} \ddot{\boldsymbol{u}}_{i+1 / 2}^{n}$

8. Calculate the nodal internal forces.

9. Compute $\ddot{\boldsymbol{u}}_{i}^{n}$

10. Second partial update nodal velocities: $\dot{\boldsymbol{u}}_{i}^{n}=\dot{\boldsymbol{u}}_{i+1 / 2}^{n}+\left(t_{i+1}-\Delta t_{i+1 / 2}\right) \ddot{\boldsymbol{u}}_{i+1}^{n}$

11. Check energy balance at time step $i+1$

12. Adaptive check for variable time step.

13. Update counter: $i=i+1$

14. Output; if simulation not complete, go to 4 . 
Table 2 Flowchart of the developed procedure

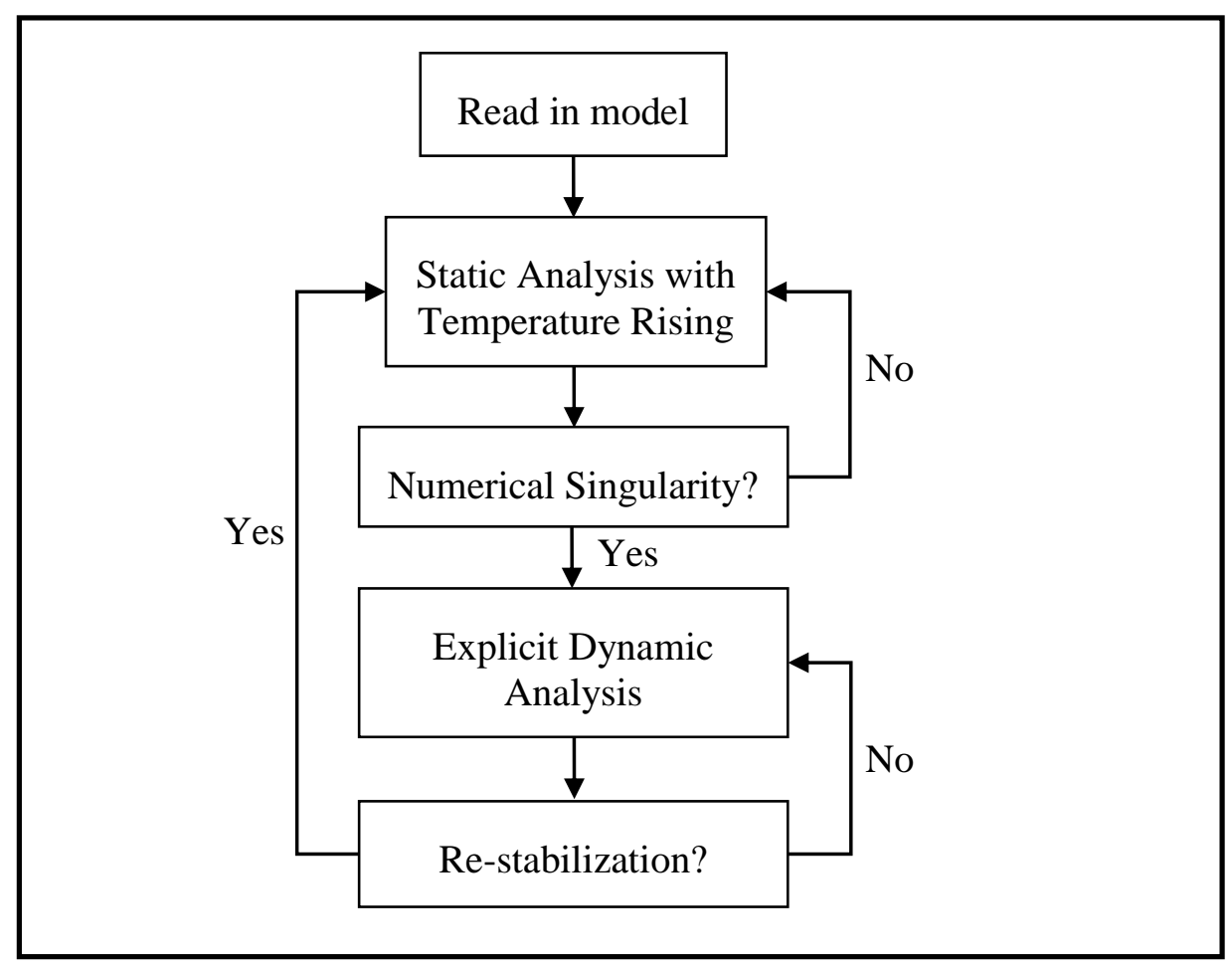

